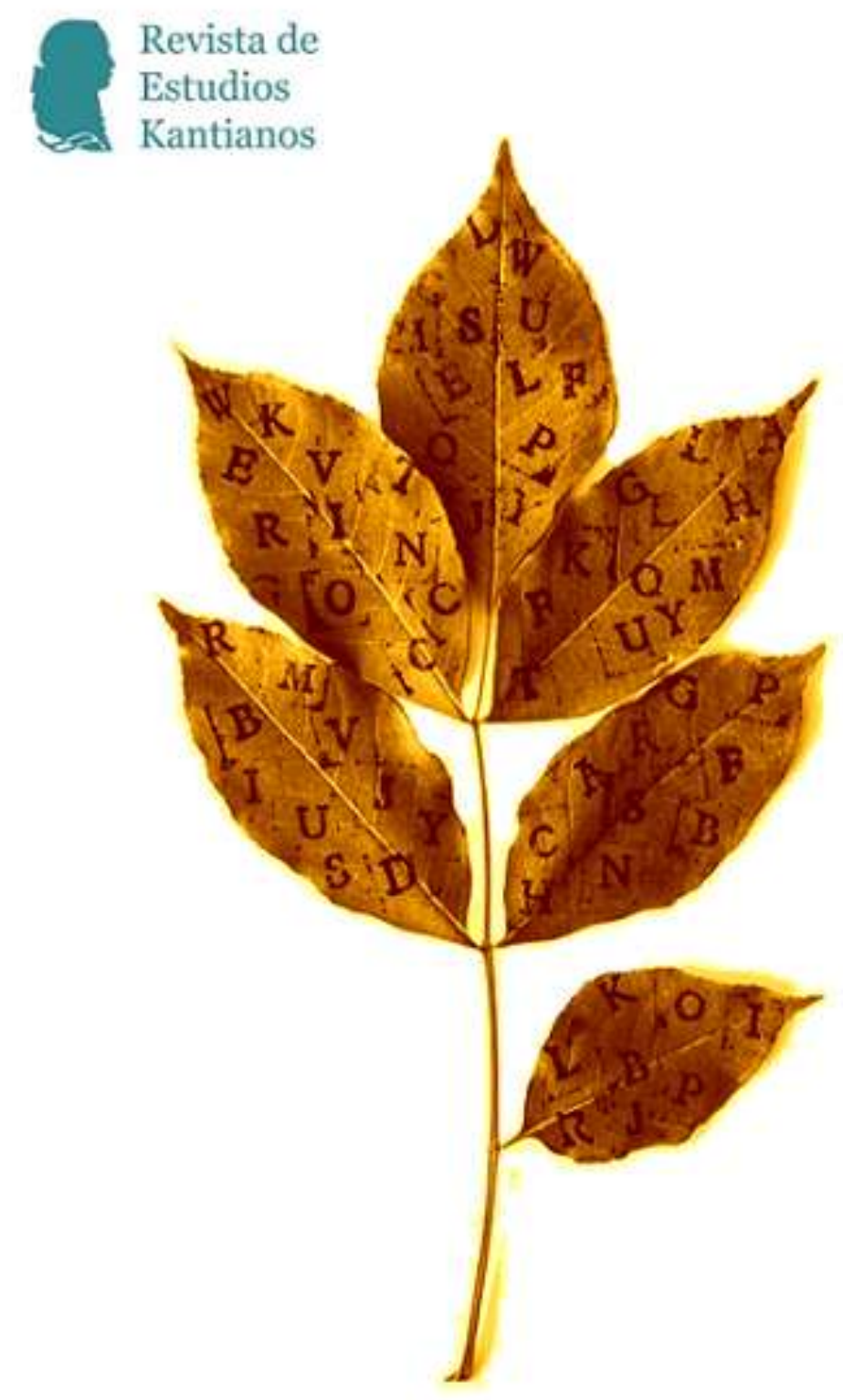




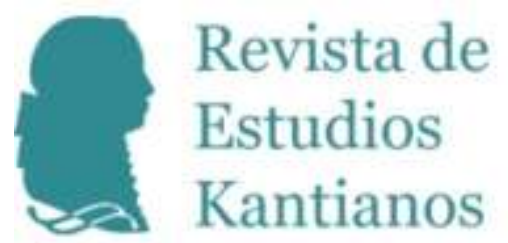




\section{Revista de Estudios Kantianos}

Publicación internacional de la Sociedad de Estudios Kantianos en Lengua Española Internationale Zeitschrift der Gesellschaft für Kant-Studien in Spanischer Sprache International Journal of the Society of Kantian Studies in the Spanish Language

\section{Dirección}

Pedro Jesús Teruel, Universitat de València

pedro.teruel@uv.es

Hernán Pringe, CONICET-Universidad de Buenos Aires/

Universidad Diego Portales, Santiago de Chile

hpringe@gmail.com

\section{Secretario de edición}

Fernando Moledo, Universidad de Buenos Aires - CONICET

fernandomoledo@gmail.com

\section{Secretaria de calidad}

Marcela García, Instituto de Investigaciones Filosóficas, UNAM

garciar.marcela@gmail.com

\section{Editores científicos}

Jacinto Rivera de Rosales, UNED, Madrid

Claudia Jáuregui, Universidad de Buenos Aires

Vicente Durán, Pontificia Universidad Javeriana, Bogotá

Julio del Valle, Pontificia Universidad Católica del Perú, Lima

Jesús Conill, Universitat de València

Gustavo Leyva, Universidad Autónoma de México, México D. F.

María Xesús Vázquez Lobeiras, Universidade de Santiago de Compostela

Wilson Herrera, Universidad del Rosario, Bogotá

Pablo Oyarzun, Universidad de Chile, Santiago de Chile

Paula Órdenes Azúa, Universität Heidelberg 


\section{Comité científico}

Juan Arana, Universidad de Sevilla

Reinhardt Brandt, Philipps-Universität Marburg

Mario Caimi, Universidad de Buenos Aires

Monique Castillo, Université de Paris-Est

Adela Cortina, Universitat de València

Bernd Dörflinger, Universität Trier

Norbert Fischer, Universität Eichstätt-Ingolstadt

Miguel Giusti, Pontificia Universidad Católica del Perú

Dulce María Granja, Universidad Nacional Autónoma de México

Christian Hamm, Universidad Federal de Santa María, Brasil

Dietmar Heidemann, Université du Luxembourg

Otfried Höffe, Universität Tübingen

Claudio La Rocca, Università degli Studi di Genova

Juan Manuel Navarro Cordón, Universidad Complutense, Madrid

Carlos Pereda, Universidad Nacional Autónoma de México

Gustavo Pereira, Universidad de la República, Uruguay

Ubirajara Rancan de Azevedo, Universidade Estadual Paulista, Brasil

Margit Ruffing, Johannes Gutenberg-Universität Mainz

Gustavo Sarmiento, Universidad Simón Bolívar, Venezuela

Sergio Sevilla, Universitat de València

Roberto Torretti, Universidad Diego Portales, Santiago de Chile

Violetta Waibel, Universität Wien

Howard Williams, University of Aberystwyth

Allen W. Wood, Indiana University

Diseño, revisión de estilo y maqueta

Josefa Ros Velasco, Universidad Complutense de Madrid

\section{Entidades colaboradoras}

Sociedad de Estudios Kantianos en Lengua Española (SEKLE)

Departament de Filosofia de la Universitat de València 


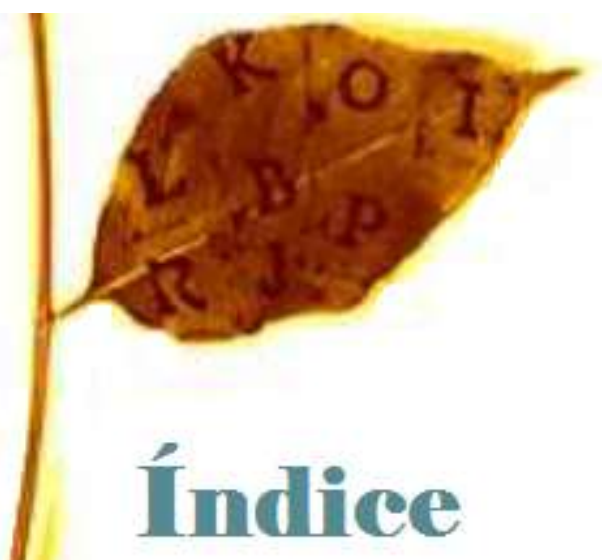

Artículos

113 ¿"El yo propiamente tal” (I. Kant) o "el originario ser sí mismo" (D. Heinrich)? Sobre algunas características del concepto kantiano de autoconciencia

Heiner Klemme

DOI 10.7203/REK.2.2.9068

126 La noción kantiana de verdad transcendental

Stéfano Straulino Torre

DOI 10.7203/REK.2.2.8809

146 Una travesía kantiana a través del Escila constructivista y el Caribdis realista. Apuntes para un abordaje kantiano-constitutivista de las fuentes de la normatividad

Martín Fleitas González.

DOI 10.7203/REK.2.2.8810

174 El malestar kantiano. Filosofía y ciencia al encuentro con la naturaleza Juan Felipe Guevara

DOI 10.7203/REK.2.2.8812

191 ¿Puede haber una fundamentación kantiana de los derechos humanos? Algunas consideraciones críticas

Nuria Sánchez Madrid

DOI 10.7203/REK.2.2.8871

\section{Semblanza}

208 El pensamiento filosófico de Ernesto Mayz Vallenilla

Gustavo Sarmiento

DOI 10.7203/REK.2.2.9021 


\section{Reseñas}

217 Claudia Jáuregi, Fernando Moledo, Hernán Pringe y Marcos Thisted (eds.) Crítica y Metafísica. Homenaje a Mario Caimi. Studien und Materialen zur Geschichten der Philosophie. Hildesheim, Olms, 2015, 460 pp. ISBN: 978-3-487-15237-0.

Alba Jiménez Rodríguez.

DOI 10.7203/REK.2.2. 8814

227 Fernando Moledo: Los años silenciosos de Kant: Aspectos de la génesis de la Deducción Trascendental en la década de 1770. Seguido de la traducción del Legado de Duisburg (ca. 1775). Buenos Aires, Prometeo, 2014, 192 pp. ISBN: 978-987-574-667-1.

Pablo Moscón DOI 10.7203/REK.2.2. 8830

231 Salvi Turró: Filosofia i Modernitat. La reconstrucció de l'ordre del món. Barcelona, Edicions Universitat de Barcelona, 2016, 228 pp. ISBN: 978-84-475-3966-6.

Pedro Jesús Teruel

DOI 10.7203/REK.2.2. 8887

233 Gabriel Rivero: Zur Bedeutung des Begriffs Ontologie bei Kant. Berlín, Boston, Walter de Gruyter, 2014, 247 pp. ISBN: 978-3-11-034180-5.

Luciana Martínez

DOI 10.7203/REK.2.2.8881

Informe

237 Informe sobre el III Congreso de la Sociedad de Estudios Kantianos en Lengua Española (SEKLE)

Luciana Martínez

DOI 10.7203/REK.2.2.9011

\section{Convocatoria}

242 La recepción de Kant en México

Dulce María Granja Castro; Gustavo Leyva Martínez

Eventos y normas para la publicación

244 Noticias y normas para autores 


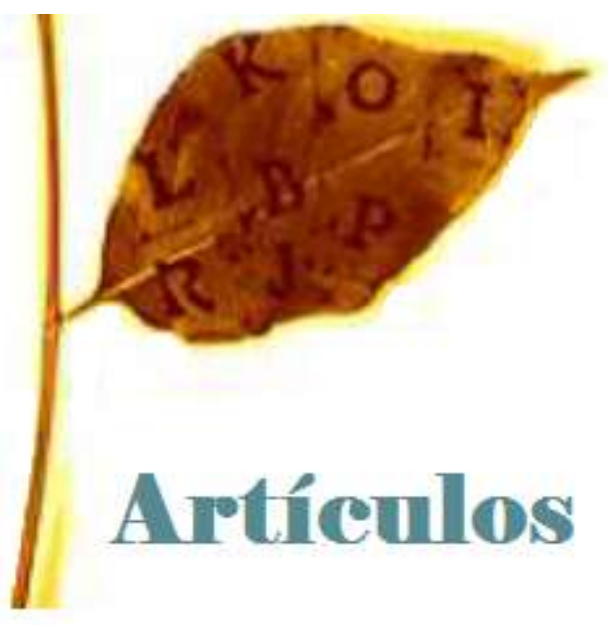




\title{
Una travesía kantiana a través del Escila constructivista y el Caribdis realista. Apuntes para un abordaje kantiano- constitutivista de las fuentes de la normatividad
}

\author{
MARTÍN FLEITAS GONZÁLEZ ${ }^{1}$
}

\begin{abstract}
Resumen
El artículo aborda el problema de las fuentes de la normatividad en el contexto de las contemporáneas disputas neokantianas. Señalando las limitaciones que muestran los enfoques constructivistas y realistas para reconstruir una lectura fiel y solvente de la ética kantiana, el trabajo sugiere una línea alternativa denominada constitutivista. Este enfoque propone una lectura performativa de los textos de Kant para defender la tesis de que las fuentes kantianas de la normatividad yacen en construcciones reflexivas de mandatos que implican, al mismo tiempo, la asunción realista del valor de la idea de libertad. La moral consistiría entonces, en autoconstituirse como agente.

Palabras clave: constitutivismo, constructivismo, fuentes de la normatividad, realismo.
\end{abstract}

A Kantian journey through the Constructivist Scylla and realist Charybdis. Notes for a Kantian-Constitutivist approach of sources of normativity

\begin{abstract}
The article addresses the problem of the sources of normativity in the context of contemporary neo-Kantian disputes. Noting the limitations that the Constructivists and Realistic approaches show to reconstruct a faithful and solvent reading of Kantian ethics, the paper suggests an alternative line called constitutivist. This approach proposes a performative reading of Kant's texts to defend the thesis that the Kantian normative sources lie in reflective constructions of mandates involving, at the same time, the realist assumption of the value of the idea of freedom. The moral would then stand in the self-constitution as an agent.
\end{abstract}

Key Words: constitutivism, constructivism, realism, sources of normativity.

Dios no quiere únicamente que seamos felices, sino que debamos hacernos felices, lo cual constituye la verdadera moralidad.

Immanuel Kant, Lecciones de ética

${ }^{1}$ Universidad de la República Oriental del Uruguay. 


\section{Introducción ${ }^{2}$}

Hace un tiempo se libran acalorados debates acerca de cómo y por qué debemos recoger el legado de la ética kantiana. En particular, tanto seguidores de Kant como estudiosos de historia de la Filosofía, han edificado todo un tópico en torno a la pregunta de cuál es la postura más fiel, y al mismo tiempo, consistente, que Kant habría asumido acerca de las fuentes de la normatividad. Es evidente que este planteo ofrece muy poca claridad; pero esta poca claridad emana de la difusa forma en que debaten los neokantianos e historiadores de la Filosofía. Pero para apreciar esto, resulta oportuno introducirnos en el debate no sin antes observar que existen allí algunas preguntas peligrosamente yuxtapuestas, que bien podrían contribuir a la confusión.

Por un lado, surge la pregunta histórico-filosófica acerca de cuál habría sido la postura de Kant acerca de las fuentes de la normatividad, tanto moral como no moral. Pero al mismo tiempo, dentro de las discusiones también hallamos otra que pregunta acerca de cuál sería la postura kantiana más consistente al respecto. Si bien tales preguntas son diferentes, parecen entremezclarse asiduamente en las discusiones actuales a causa de varios factores, siendo el principal de todos ellos el de la 'extrañeza' que presenta el lenguaje del problema de la normatividad frente al lenguaje utilizado por Kant.

Es esta extrañeza de la terminología de las fuentes de la normatividad la que ha llevado a los filósofos contemporáneos ha embanderarse en dos frentes, en apariencia irreconciliables: por un lado, un frente que sostiene que Kant habría defendido una teoría del valor 'proyeccionista', mientras por otro, un frente que entiende que Kant habría asumido un modelo 'detectivista'. Sirviéndome de la bien conocida terminología de Langton, el enfoque 'proyeccionista' del valor 'endorses the biconditional "something is good just in case it is an object of rational choice", [by] giving " "priority" (however we spell that out) to the right-hand side of the biconditional' (Langton 2007: 172); desde esta perspectiva, $X$ sería bueno en la medida en que haya sido objeto de elección racional. Mientras por su lado, el enfoque 'detectivista' pone su énfasis, o 'prioridad', en el extremo izquierdo del biciondicional, es decir, en el lado que afirma que X sería un objeto de elección racional en razón de que $\mathrm{X}$ es bueno.

El dilema de Eutifrón revive para dividir las aguas en torno a cómo comprender la ética kantiana, sus alcances y sus limitaciones: ¿es el agente el que atribuye bondad a posibles objetos de nuestra voluntad mediante su capacidad de establecer fines, o acaso los fines representan bondades que la capacidad racional del agente descubre durante su reflexión? Si bien parecen ser estos términos los que han delimitado la discusión, me temo que no hay razones convincentes para asumir aproblemáticamente el dilema. Resulta evidente que la ética kantiana puede ser leída con ambos prismas, en virtud de que existe suficiente sustento textual como para sostener ambos enfoques. Si nos detenemos en la primera y segunda formulación del Imperativo Categórico (en adelante IC), seguramente podamos elaborar desde allí una versión procedimental de la moral y la justicia muy cercana a la de Rawls, O`Neill o Habermas. Esto implicaría una teoría proyeccionista del valor que en principio podría funcionar, y ser bastante convincente, pero que rápidamente se encontraría en problemas a la hora de justificar la incondicionalidad del valor de toda persona. El escollo podría resumirse como sigue: si todo fin es valioso en virtud de que ha sido determinado racionalmente (sea mediante IC o deliberación de todos los afectados) ¿por qué no sería racional degradar el valor de ciertas personas, o incluso la propia, durante una toma de decisión? Aquí es donde el enfoque detectivista asegura que son las incondicionalidades de los valores de la Humanidad, Autonomía, y del Reino de los Fines, las que se le imponen al agente durante su toma de decisión. Postura que, al mismo tiempo, nos lleva a asumir algún tipo de realismo axiológico que bien podría amenazar las innegables pretensiones cognitivas y universales de Kant.

Ciertamente, el constructivismo y el realismo han complejizado el debate, amén de considerar la posibilidad de que la terminología no haga justicia a la originalidad que Kant podría

\footnotetext{
${ }^{2}$ Gran parte de la redacción de este trabajo se ha visto incalculablemente favorecido por la asistencia que me han brindado Raluca y Ana Ciortea. Sirva esta nota para expresar mi profunda gratitud hacia ellas.
}

Nota del editor: artículo premiado con la segunda mención SEKLE. 
haberle impreso a su ética. Pienso que, así como Platón pone en boca de Sócrates la solución al dilema de Eutifrón, es razonable sostener la idea de que el lenguaje proyeccionista y detectivista pudiera no capturar la singularidad de la ética kantiana, a causa de que esta última bien podría asumir una teoría del valor compuesta por elementos tanto atributivos, como receptivos.

En el presente trabajo me propongo convertir esta última sugerencia en una tesis fundamental. La argumentación que presentaré en su favor se conforma de cuatro partes: en primer lugar reconstruiré los enfoques constructivistas de Rawls y O'Neill con el objeto de identificar sus características más distintivas, al mismo tiempo que sus limitaciones a la hora de abordar la cuestión de las fuentes de la normatividad. Luego desarrollaré una tarea análoga sobre los enfoques realistas de Wood y Sensen, por entenderles los detectivistas más representativos. En tercer lugar abordaré el enfoque de Korsgaard, a quien no incluyo dentro de los constructivistas a pesar de sus explícitas declaraciones. Como veremos, su postura acerca de la relación que mantienen el agente, la ley y la identidad práctica, abriga tanto consecuencias constructivistas como realistas. Pero no deseo interpretar las ambigüedades de su enfoque como insuficiencias tan sólo teoréticas, sino también como insuficiencias inherentes al lenguaje constructivista-realista para dar con la originalidad de la ética kantiana. En este contexto, es el análisis de la insuficiencia del lenguaje contemporáneamente utilizado el que me permitirá argumentar en favor de un modelo kantiano 'constitutivista' que entiendo más consistente. La tesis que defenderé es la de que tanto la construcción como la asunción de un valor absoluto, en particular el de la idea de libertad, se encuentran irrenunciablemente entrelazados en toda reflexión emprendida por el agente, una vez que este desea responder a la pregunta ‘¿qué debo hacer?' El principal argumento que desarrollaré en favor de tal tesis consistirá en iluminar las implicaciones performativas de la reflexión práctica inherentes al enfoque de la ética kantiana. Estas implicaciones performativas pondrán de relieve bases suficientes como para bocetar un modelo constitutivista de las fuentes kantianas de la normatividad, el cual, en pocas palabras, sostiene que las fuentes de la normatividad nacen de la reflexión que despliega el agente al elaborar una regla práctica que oriente su conducta; una reflexión que en modo alguno puede emprenderse si al mismo tiempo no se asume la realidad de un valor absoluto como el de la libertad. Estas implicaciones performativas de la reflexión práctica 'constituyen' al agente como agente, y en virtud de ello es que el modelo constitutivista aspira a absorber los aportes más valiosos del proyeccionismo y detectivismo.

\section{El constructivismo neokantiano}

El constructivismo neokantiano constituye una de las herencias kantianas más robustas de los siglos XX y XXI. Distinguidos filósofos se han afiliado a esta tradición: John Rawls, Onora O'Neill, Frederick Rauscher, Karl-Otto Apel, Jürgen Habermas, Carlos Nino, e incluso Christine Korsgaard (vid. Apel 1998; Habermas 1985; Nino 1989; Rauscher 2002). No obstante, planeo aquí concentrarme en los enfoques de Rawls y O’Neill en virtud de ser los más influyentes y fundantes del proyeccionismo actual, así como también de los términos de la discusión vigente. Es verdad que el enfoque de O’Neill es muy cercano al programa de justicia de Rawls, pero veremos que la originalidad de la filósofa consiste en imprimir sendas reformulaciones a la propuesta de este último, ganando con ello una mayor cercanía a Kant y a sus pretensiones universalistas.

\subsection{John Rawls y la fundación del constructivismo neokantiano}

Según O’Neill, el constructivismo de Rawls surge del esfuerzo por trazar un puente capaz de superar los embates del relativismo y del realismo (O’Neill 1989: cap. 2). Así es que Rawls introduce por primera vez el término 'constructivismo' con claras pretensiones anti-realistas, pues Rawls es antirealista en la medida en que intenta mantenerse al margen de cualquier reclamación metafísica trascendente, para al mismo tiempo, evitar el relativismo inherente a las concepciones de vida buena mediante la determinación de principios de justicia susceptibles de aceptación por parte de todos aquellos que se vean afectados. En palabras de Rawls, su teoría "it specifies a particular conception of the person as an element in a reasonable procedure of construction, the outcome of which determines the content of the first principles of justice", pretendiendo con ello "to establish a suitable connection between a particular conception of the person and first principles of justice, by means of a procedure of construction" (Rawls 1980: 516) Rawls es cuidadoso en distinguir su declaración del 
constructivismo kantiano de los propios puntos de vista de Kant: "Justice as fairness is not, plainly, Kant's view, strictly speaking; it departs from his text at many points" (Rawls 1980: 517). Por su parte, Rawls llama 'constructivo' al modo de establecer una conexión entre una determinada concepción de persona y los principios fundamentales de justicia, dado que se supone que la conexión no se establecerá por medio de una:

search for moral truth interpreted as fixed by a prior and independent order of objects and relations, whether natural or divine, an order apart and distinct from how we conceive of ourselves (...) What justifies a conception of justice is not its being true to an order antecedent to and given to us, but its congruence with our deeper understanding of ourselves (...) Kantian constructivism holds that moral objectivity is to be understood in terms of a suitably constructed social point of view that all can accept (Rawls 1980: 519).

Una vez esbozados los rasgos básicos de su modalidad constructivista, Rawls elabora un novedoso conjunto de herramientas con el objetivo de conectar su concepción no metafísica de persona con los principios fundamentales de justicia. En particular, piensa que tales principios se pueden establecer por medio de un proceso de 'equilibrio reflexivo' desde dentro de una 'posición original', la cual se define por cierta restricción informacional, o 'velo de la ignorancia', que cae sobre los agentes. La idea básica de esta propuesta recae en que los principios fundamentales de justicia pueden construirse mediante la determinación de lo que los agentes elegirían luego de reflexionar desde detrás del velo de la ignorancia, acerca de su situación vigente y futura, sin saber ni quiénes serían ni cuáles sus deseos personales. Dado que el recurso del velo de la ignorancia descarta cualquier información específica de la cual dichos agentes puedan valerse para obtener una ventaja injusta, aún para ellos mismos, lo principios que elegirían en tal situación tendrían que ser justos.

Sin embargo, el velo de la ignorancia no puede excluir toda la información y todos los deseos personales, puesto que en el caso de que los agentes participantes de la posición original no tengan ninguna orientación para la selección y elaboración de los principios, por extensión tampoco buscarían que los principios sean justos. Como resultado, Rawls parecería violar el velo de la ignorancia al permitir el conocimiento de la conveniencia universal de bienes primarios como los derechos, las libertades y la riqueza en la posición original. El permiso que Rawls le concede a esta selección informacional tiene el objetivo de ofrecer a los agentes de la posición original, los rudimentos reflexivos básicos y mínimos como para luego, a partir de ellos, poder construir los principios fundamentales de justicia.

Pero es justamente en este punto en donde O’Neill apuntala su principal objeción contra Rawls, preguntando por la justificación que posee la concepción de persona definida en su posición original. Evidentemente, a esta pregunta no se le puede hacer frente recurriendo a alguna antropología filosófica subyacente, puesto que esto implicaría de por sí un supuesto realista. Así es que Rawls, según O'Neill, "let alone the suspect Kantian account, of the metaphysics of the self" o, de forma más peyorativa, "obscure and panicky metaphysics" (O’Neill 1989: 210). En virtud de ello, en última instancia Rawls parecería favorecer la alternativa de admitir que "we are not trying to find a conception of justice suitable for all societies regardless of their particular social or historical circumstances" (Rawls 1980: 518). Sin embargo, como O'Neill observa acertadamente, "far from deriving a justification of democratic citizenship from metaphysical foundations, Rawls [can vindicate only] those deep principles of justice 'we' would discover in drawing on 'our' underlying conceptions of free and equal citizenship. This vindication of justice does not address others who, unlike 'us', do not start with such ideals of citizenship; it has nothing to say to those others. It is 'our' ideal, and 'our' justice" (O’Neill 1989: 211). Por lo que O’Neill concluye que el constructivismo rawlsiano no es, a pesar de todo, distinto del relativismo que intentaba superar.

Aún quedaría por verse el hecho de si realmente este tipo de objeción representa una controversia para el programa de Rawls, o en otras palabras, si la objeción de O'Neill constituye una razón determinante como para renunciar al programa rawlsiano. Puesto que en varias oportunidades la 'superación' del relativismo, por parte de Rawls, no implica eliminarlo sino más bien encontrar 
puntos equidistantes a todo pluralismo inherente a una sociedad bien ordenada ${ }^{3}$, la objeción de O'Neill debería entenderse mejor desde el punto de vista del kantismo y su herencia universalizante. En pocas palabras, O’Neill parecería, en el fondo, objetarle a Rawls que con su versión reducida del constructivismo ha despojado a la herencia kantiana de toda su original pretensión universal hacia la humanidad. Así es que O'Neill se pregunta si Rawls no se ha desviado en algún punto. Dado que O'Neill se siente atraída por el constructivismo, es para ella crucial identificar y luego eliminar aquella característica del enfoque de Rawls que le impide ser satisfactoria; y esta característica deficiente, en opinión de O’Neill, sería su ideal de persona subyacente.

Según O’Neill, las dificultades de Rawls emanan casi por completo del ideal de persona subyacente a la posición original. En lugar de abstraer algunas características fundamentales del agente, Rawls defiende una idea de persona restringida a la democracias liberales: “(I)dealization masquerading as abstraction produces theories that may appear to apply widely, but in fact covertly exclude from their scope those who do not match a certain ideal. They privilege certain sorts of human agent and life by presenting their specific characteristics as universal ideals" (O'Neill 1989: 210). En consecuencia, una vez que Rawls ha idealizado agentes en la posición original como medio de justificación, restringe, al mismo tiempo, su aplicación para las sociedades democráticas occidentales (O’Neill 1989: 212).

\subsection{El constructivismo neokantiano de Onora O’Neill}

Si O'Neill está en lo cierto acerca del constructivismo de Rawls, por un lado se evidencia su objetivo de querer actualizar un kantismo universalista, mientras por otro quedan aún por determinarse los caminos para lograrlo. La estrategia de O'Neill en principio es simple: en lugar de invocar un velo de ignorancia que se ha incumplido de manera selectiva con el fin de permitir en la posición original un conjunto limitado de deseos, y cuya satisfacción ha de ser maximizada por la razón instrumental, lo que O'Neill sugiere es que el principio operativo de la construcción derive de responder a la pregunta modal "¿qué principios puede aceptar una pluralidad de agentes de racionalidad mínima y capacidades indeterminadas de independencia mutua?” (O’Neill 1989: 213, 1996: 52).

A diferencia del programa rawlsiano, los deseos no son el determinante fundamental dentro del procedimiento constructivista de O'Neill, así como tampoco lo es una racionalidad instrumental en conexión con los deseos. La noción fundamental para O'Neill es la posible agencia de una pluralidad de distintos, pero relacionados entre sí como seres racionales. Su propuesta puede generar principios normativos prácticos porque "there are certain constraints on the principles of action that could be adopted by all of a plurality of potentially interacting agents of whom we assume only minimal rationality and indeterminate mutual independence. Principles that cannot be acted on by all must be rejected by any plurality for whom the problem of justice arises" (O'Neill 1989: 215). Para ilustrar su idea, O’Neill muestra cómo los principios de la coerción, la violencia y el engaño evidencian violaciones de primer orden para los principios de la justicia, al implicar el hecho de que no se puede actuar ni aceptar una norma en nombre de todos los afectados por ella, ya que la coacción, la violencia y el engaño, socavan la agencia racional o el asentimiento de al menos algunos agentes, a saber, la de los que serían coaccionados, perjudicados o engañados por tales principios. En lugar de invocar la razón instrumental con el fin de satisfacer la mayor cantidad posible de un conjunto selectivo de deseos, la versión constructivista de O'Neill busca asegurarse de la posibilidad de que los agentes a tener en cuenta en su consentimiento, y acción, participen efectivamente en la elaboración de los principios prácticos que les involucren. Al comenzar con un conjunto de agentes que abstrae sus deseos, y al mismo tiempo dejando un resto de mínimos de racionalidad intacto para asegurar la acción-participación de todos estos agentes implicados, O’Neill asegura que su versión del constructivismo es significativamente distinto al de Rawls.

De acuerdo con esta descripción de la propuesta de O’Neill, el problema del relativismo parece ser evitado sin caer en ninguna afirmación metafísica inaceptable. Mientras que Rawls se vio

\footnotetext{
${ }^{3}$ Recuérdese el caso de Lincoln, y su evocación al castigo divino en nombre de la abolición de la esclavitud, analizado por Rawls con el objetivo de mostrar la necesidad de conectar o anclar los principios de justicia en ideas de vida buena (Rawls 1996: 283287).
} 
obligado a aceptar aquel relativismo dentro del cual los principios resultantes de un procedimiento constructivista pudiesen ser aceptados, esto es, sólo por aquellos que comparten la concepción ideal de un agente integrado en su fundación, la propuesta de O'Neill se aplicaría a todos los agentes racionales con los que se pueda interactuar. Al mismo tiempo, ella no necesita apelar a trasfondos metafísicos controvertidos o ideales de persona justificados, lo cual le convence de que ha desarrollado una versión del constructivismo superior al de Rawls.

Sin embargo, precisamente porque su enfoque no idealiza en la forma en que Rawls lo hace, ella se enfrenta a un reto importante que Rawls evita desde el principio, a saber, el de ofrecer una explicación acerca de la fuerza normativa de los principios que se derivan del procedimiento constructivo. Mientras para este punto Rawls cuenta con la aceptación de los ideales de la sociedad occidental implícitos a la posición original, O'Neill debe acudir a otro recurso en la medida que rechaza estos ideales. Si los principios prácticos tienen fuerza normativa y estos principios son el resultado de procedimientos constructivos, a continuación, los procedimientos constructivos deberían ser responsables de la generación de la fuerza normativa. Sin embargo, los procedimientos constructivos no pueden generar fuerza normativa, si es que aún no poseen autoridad normativa. Al mismo tiempo, no está claro cómo un constructivista podría afirmar que los procedimientos constructivos tienen autoridad normativa intrínseca, si se basan simplemente en ciertos hechos morales generales.

Para responder a estas cuestiones O'Neill argumenta que el procedimiento constructivo puede producir la fuerza normativa de los principios resultantes mediante la aplicación de la siguiente línea de pensamiento (O’Neill 1989: caps. 1 y 2; 1996: cap. 2): 'si y solo si' el procedimiento constructivo se basa en la razón, entonces es razonable pensar que sus principios puedan tener fuerza normativa, en virtud de que la razón, y no el procedimiento, es la que posee la autoridad necesaria como para generar tal fuerza coercitiva. Pero al considerar si la razón tiene una autoridad normativa tal, surge naturalmente el siguiente dilema que enfrenta cualquier justificación de la autoridad de la razón: a diferencia de cualquier otra cosa, la razón que justifica la autoridad de sus construcciones también debe reivindicar su propia autoridad. Si se supone algo ajeno a la razón para justificar su autoridad, entonces también se interpondría en necesidad de reivindicación y no se habría hecho ningún progreso, pues siempre podríamos preguntarnos ad infinitum si ese factor en particular era racionalmente justificado. Esto hace que la simple apelación a la 'razón en sî' nos precipite hacia un desfondamiento en la argumentación: ¿cómo podría la razón justificar su propia autoridad? (O’Neill 1996: 48).

La propuesta de O'Neill gira en torno a su idea de racionalidad mínima, la cual se apoya sobre una cierta forma de interpretar al sujeto trascendental: un sujeto intersubjetivo que 'construye' el mundo al igual que las normas morales y públicas, por el hecho mismo de ser inevitable el compartir un 'mismo mundo'. Una construcción que asume como 'disciplina' de la razón aquellas máximas del uso público de la razón esbozadas por Kant en ¿Qué es la Ilustración?: a) piensa por ti mismo, sírvete de tu propia razón, b) piensa desde el punto de vista de todos los demás, y c) siempre piensa consistentemente.

O'Neill responde a este dilema con el argumento de que la autoridad de la razón puede ser justificada sólo de forma recursiva y en un contexto público o político. Ella sugiere que deberíamos tomar en serio tanto la noción del uso público de la razón que Kant emplea en ¿Qué es la Ilustración?, así como también las metáforas políticas dispersas en Crítica de la Razón Pura. Según O’Neill, el uso público de la razón no apela a ninguna autoridad externa, ninguna autoridad que no pueda ser aceptada por una pluralidad de agentes racionales. Por lo tanto, independientemente de qué tan extenso sea su público, la declaración de un sacerdote del altar no es pública en el sentido de O'Neill ya que el sacerdote habla desde el punto de vista de alguien que acepta una autoridad distinta de la razón, y frente a una audiencia limitada que acepta dicha autoridad. De este modo, la única autoridad a la que puede recurrirse durante el uso público de la razón es aquella que está implícita en, o interna a, los estándares del discurso público mismo.

Una justificación metafísica de la fuerza normativa de la razón se descarta sobre la base de su rechazo de la metafísica trascendente: "(T)here is no lofty position above the debate, as perhaps 
there might be if human reason had a transcendent source" (O'Neill 1989: 46-47) Una justificación teológica se descarta dado el hecho de que los agentes son independientes y autónomos, y de hecho, cualquier tipo de justificación que no se base en las normas inherentes al debate público será desechada: "since the world at large accepts no common external authority, the only authority the communication can assume must be internal to the communication" (O'Neill 1989: 35). Por este motivo la razón no tiene ningún fundamento trascendente más que aquel que se basa en un cierto tipo de acuerdo. El mero acuerdo, si fuera posible, no tendría ninguna autoridad. Lo que empodera a un acuerdo de cierto tipo de autoridad es el hecho de que se basa en un acuerdo sobre los principios que cumplen su propia crítica, esto es, el hecho de ser acuerdos reflexivos (O’Neill 1989: 38). De ahí que sea la recursividad o reflexividad la clave jutificatoria de la razón y, por lo tanto, de los principios prácticos basados en ella: recursividad patente en aquellas normas que puedan ser aceptadas por una pluralidad de agentes racionales que participen en el discurso público.

\subsection{Limitaciones del constructivismo neokantiano}

Es por demás evidente que el haberme enfocado en las solas posturas de Rawls y O'Neill violenta la diversidad de matices que podemos hallar dentro de la vertiente constructivista neokantiana. No obstante, presentaré algunas limitaciones que aquejan tanto a estos enfoques como al constructivismo en general. En primera instancia, me detendré en la bien conocida objeción que ha recibido la rígida distinción kantiana, luego asumida por muchos scholarships, entre inclinaciones y racionalidad.

En principio, la distinción que Kant intenta establecer tan fuertemente en el primer capítulo de su Fundamentación, entre inclinaciones y racionalidad moral, puede reformularse en términos de vida buena y moralidad. El problema sucintamente descrito sería el siguiente: si la racionalidad moral o de justicia sólo ha de restringirse a las razones universalizables, razonables y compartibles por otros, las cuestiones de vida buena o bien desparecen, o bien son irracionales.

En su larga discusión con Habermas, Hilary Putnam formula esta objeción de forma bastante clara: si bien en Kant no está claro, sí es evidente que en muchos de sus seguidores se encuentra la explícita defensa de una idea de racionalidad que amenaza con diluir las cuestiones de vida buena en leyes universalizables, o con convertirlas en irracionales en virtud de que comúnmente son entendidas como personales y privadas, aun intersubjetivamente mediadas, pero a fin de cuentas no compartibles por definición (Putnam 2004: 133-158). Esta es una dura objeción que, si bien en el caso de Korsgaard es más vidrioso dado el 'realismo procedimental' que defiende en la tercera conferencia de sus Kantian Lectures, en el caso de la mayoría de las versiones constructivistas resulta algo estremecedor. Pues, si la autoridad de la razón es por definición pública, ¿qué status racional tienen las razones inherentes a la vida buena no compartibles? ¿Acaso los constructivistas comparten con Korsgaard la idea platónica acerca de que se requiere del imperio de la razón para poner en orden las partes irracionales del alma, de la ciudad, y en la actualidad, de la pluralidad de ideas del bien para procurar la convivencia universal? (Korsgaard 2000: 284).

Desde esta observación crítica hay tan sólo un paso hasta aquella que las feministas han forjado tan letalmente acerca del encubrimiento inherente a la racionalidad abstracta, 'posconvencional' del 'otro generalizado', que subyace: un 'machismo' filosófico que homologa la racionalidad con el rol público, hasta hace poco tan sólo desempeñado por los hombres. Filósofas como Seyla Benhabib (1986) y Marion Iris Young (1986) muestran que desde este punto de vista, las 'éticas del cuidado', los proyectos de felicidad y la vida privada pasarían tendenciosamente a ser consideradas como irracionales al no ser compartibles sus razones inherentes, excluyendo su tematización y reflexión de todo ámbito público, y con ello, ciertas formas generalizadas de procederes éticos tradicionalmente vinculados con la femeneidad.

Sin embargo, resulta por demás evidente que este tipo de objeciones nacen de las ya bien conocidas críticas que Hegel le realizara a Kant. En este caso, resulta oportuno tan sólo mencionar aquellos parágrafos en los que Hegel, incluso irónicamente, critica el modelo contractual del matrimonio de Kant. En § 75 y § 163 de su Rechtsphilosophie, el punto principal de la objeción radica en la tesis de que la percepción unilateral del matrimonio o de la familia, en cuanto relación jurídica meramente formal, incapacitaría a los individuos de participar en las prácticas comunicativas de 
ayuda y cuidado mutuos ${ }^{4}$. $\mathrm{Y}$ en este sentido, algo similar sucede con la libertad moral: el distanciamiento que ha de asumir el agente frente al mundo de la vida que abriga las inclinaciones, pseudocosifica la idea de libertad de tal modo que amenaza con vaciar de normatividad al mismo IC (§ 135).

Por otro lado, y en conexión con esta tradicional objeción, deseo incorporar una segunda crítica que los constructivistas han padecido durante algún tiempo, especialmente luego de los ' 90 , por parte de los realistas. Tal objeción recae en cómo determinar, desde la perspectiva constructivista, el valor de los demás como un fin en sí mismo, así como el valor propio. Usualmente los constructivistas suelen responder que todo aquello que constituye un valor, sea moral o no moral, depende de que efectivamente la razón lo haya vuelto tal, es decir, lo haya considerado como un bien. Teniendo en mente y de forma estricta aquellas líneas en las que Kant dice "(N)ihil appetimus, nisi sub ratione boni" ["Nada apetecemos que no se halle bajo la razón de lo bueno"] (KpV 59), los constructivistas suelen defender la idea de que la racionalidad, esto es, 'la capacidad de establecer fines', es la única fuente de valor, lo que la convierte en la única cosa portadora de un valor incondicionado.

Aunque su enfoque sea ligeramente distinto al de Rawls y O'Neill, el caso de Barbara Herman también se alinea a este posicionamiento. La peculiaridad de Herman consiste en seguir al pie de la letra a Kant, cuando este afirma que lo único pensable en el mundo, cuyo valor sea incondicional, es la buena voluntad. Ella sostiene que 'sólo' una "(F)ull conformity to what pure practical reason requires" puede constituir un 'valor' moral fundamental, mientras la Fórmula de la Humanidad "adds no independent value content to the idea of conformity to the principles of practical rationality". De esta manera es que, si bien su enfoque pretende 'abandonar' el deontologismo, Herman asume una teoría proyeccionista del valor (Herman 1993b: 216, incluyendo nota 17).

No obstante, varios realistas atacan este 'valor moral fundamental' como un punto ciego del constructivismo, pues, de la premisa ' $R$ es la fuente de valor de las cosas' no se sigue ' $R$ es algo invaluable', sino que por el contrario, parecería más bien seguirse que tal valor, absoluto al fin, constituye un valor pre-existente a la acción de valorar algo, dando lugar así al realismo (Wood 1999: 91-92; Hills 2008: 186) ${ }^{6}$. Un constructivista difícilmente diría que tal valor pre-existe al ejercicio de la racionalidad, sino que, por el contrario, constituye un valor porque ella se valoriza de tal forma a sí misma. De este modo la inviolabilidad de una persona recaería en su calidad de participante del discurso, sea en una posición original, situación ideal de habla, o deliberación sin más, puesto que allí la razón se identificaría a sí misma de forma recursiva, valorizándose a sí misma mediante el consenso.

Este tipo de argumentación constructivista parece, aún en su variedad de formulaciones, ser fiel a la metodología lógica que Kant utiliza para elaborar la forma adecuada del IC: la ley no debería dar lugar a un mundo en el cual la máxima que le ha forjado se destruya. El principio de no contradicción constituye la piedra angular de todo constructivismo en virtud de que parecería ser impensable, o más bien, 'irracional', el que la racionalidad pueda contradecirse y autodestruirse. Así es que la racionalidad práctica, debido a su cualidad de 'fuente de valor', ha de ser considerada por sí misma como algo inestimable, como la condición de posibilidad del ejercicio de la racionalidad misma.

Sin embargo, creo que lo más importante en este punto es que el constructivismo no contempla la posibilidad de que podría no ser así, calificando tal cosa como irracional, distorsionada y sin sentido, conectándonos con la objeción anterior. La racionalidad podría no considerarse como un bien inestimable, conditio sine qua non podríamos luego considerar ningún otro bien. Y ciertamente esto es lo que atrapa mi atención: ¿por qué alguien perdería su agencia moral si decidiese, autónomamente, renunciar a ejercer tal agencia moral en nombre de otra cosa que considera más

\footnotetext{
${ }^{4}$ Véase el detallado análisis que Barbara Herman ha realizado acerca de la controversia entre Kant y Hegel en torno al matrimonio contractual (Herman 1993a).

${ }_{5}^{5}$ Las traducciones de KpV, GMS y MAM que recojo aquí son las de Roberto R. Aramayo, presentes en Kant, tomo II, Madrid, Gredos, 2010.
}

${ }^{6}$ Acerca de la discusión de los argumentos de regresión al infinito hablaré más adelante. 
valiosa, como su felicidad? Pues porque Kant expresa claramente que esto sería imposible de ser deseado sin contradicción (GMS 423). Pero ¿en contradicción con qué? Con la voluntad, en virtud de que la voluntad es racionalidad práctica, y esta a su vez, la capacidad racional de establecer fines (GMS 427), puesto que todo bien deseado lo es porque es considerado racionalmente (cf. KpV 59).

Pero, parafraseando las célebres palabras con las que Albert Camus inicia El mito de Sísifo: sólo cuando nos preguntamos acerca de por qué no suicidarse es que comienza la Filosofía. Evidentemente, que alguien decida suspender su agencia racional no implica que sea irracional, más aún si utiliza su 'capacidad racional de establecer fines' para anteponer su felicidad al ejercicio de su agencia moral. Desde la rígida perspectiva constructivista neokantiana, las inclinaciones hacia la felicidad que bien podrían suspender o inhibir la agencia moral, caerían irremediablemente en irracionalidad, sea por ejemplo el intento de otorgarle un sentido a la propia existencia racional. No estoy seguro de si el mismo Kant cae en esta homologación entre racionalidad y facultades morales ${ }^{7}$, pero sí me parece correcto afirmar que, a la luz de las observaciones precedentes, el suelo constructivista neokantiano aún siente vivamente los movimientos tectónicos de las viejas críticas que Hegel le realizara a Kant.

\section{El realismo neokantiano}

Si bien el realismo parece abrigar menor impacto en las discusiones vigentes acerca de las fuentes de la normatividad, lejos está de desvanecerse; más bien parece mostrar síntomas de muy buena salud.

En rasgos generales, los neokantianos realistas se han conformado alrededor de la tarea de responder a las críticas de rigorismo y formalismo que se le han realizado a la ética kantiana. Para responder a estas objeciones, usualmente implementan estrategias argumentales que les llevan por el camino de la pregunta acerca de por qué el ser humano posee una capacidad racional facultada de elaborar fines, o de fundar máximas en razones, o incluso, de por qué esta capacidad ha de ser digna de ser reverenciada. En este contexto reconstruiré dos tipos de realismo neokantiano que a mi juicio, si bien es relativo lo concerniente a sus influencias, ilustran las fortalezas y debilidades del realismo en general. Por un lado me concentraré en la influyente postura de Allen Wood, y por otro en la aguda propuesta de Oliver Sensen.

\subsection{El Kant realista de Allen Wood}

El objeto inicial de Wood es romper con la alianza que tradicionalmente se ha trazado entre la 'buena voluntad' y el 'actuar por deber', mostrando que la buena voluntad ciertamente posee momentos en los que se identifica con la acción por mor del deber, pero que al mismo tiempo posee instancias en las que esto no se sucede. Ejemplo de esto podrían significar las radicales diferencias que Kant encuentra entre la voluntad santa y la buena voluntad: mientras la voluntad santa se identifica con el deber, y por ello la obediencia a su propia ley no tiene cabida ni sentido, la buena voluntad requiere de ciertas disposiciones comportamentales que cooperen con el cumplimiento del deber. La veta por donde ingresa la tesis de Wood es aquella que abre Kant al preguntarse por la realidad empírica de la acción moral. Pasajes bien conocidos son aquellos en los que Kant confiesa que rara vez tiene lugar una acción moral en nuestra vida cotidiana, y que en definitiva, estas constituyen "acciones de las que quizás el mundo no ha dado todavía ejemplo alguno hasta la fecha" (GMS 408). Esto se debe a que Kant es consciente de nuestras limitaciones gnoseológicas, pues, a la luz de las conclusiones de $\mathrm{KrV}$, no tenemos modo de conocer si los motivos que orientan las acciones de los demás y las propias, son auténticamente morales (GMS 407). En base a ello, Wood nos insta a liberarnos de la amalgama "buena voluntad-acción por deber", que vacía el 'valor' de la acción moral al entenderla inexistente (Wood 1999: 22).

Wood considera que el valor moral aún condicionado de la acción de una buena voluntad no orientada por el deber podría ser el de actuar de 'acuerdo al deber'. Lo que en sus palabras sería una

\footnotetext{
${ }^{7}$ Algunos lectores del prólogo de la Fundamentación han confundido los recaudos heurísticos de Kant con omisiones de aspectos vitales irrenunciables de la vida humana. Al respecto es preciso tener en cuenta que en KpV 93, Kant enfatiza que el proceder analítico mediante el cual se identifican los componentes puros de la acción moral no implica en modo alguno "renunciar a las demandas de la felicidad", sino tan solo en lo que atañe a su investigación filosófica.
} 
"good will, but not acting from duty". Sin embargo, esto parecería pasar por alto el escollo del mundo fenoménico y nouménico que siempre opera como trasfondo en las reflexiones kantianas. Evidentemente, aún con una educación orientada a adecuarse al cumplimiento del deber, los móviles de la acción abrigarían siempre en su seno un sustrato de 'amor patológico' que bien podría ser alimentado por alguna forma de fanatismo, perdiendo así el aporte más significativo que usualmente se le atribuye a la ética kantiana: el criterio de corrección.

Sobre este punto la posición de Wood es bien particular. Desde su perspectiva, Kant parecería no querer decir nada acerca de qué es una buena voluntad, ni de cómo reconocerla, dando lugar a la posibilidad de pensar que las acciones morales no ocurren por el sólo deber sino que para su realización requieren de aditivos prudenciales. Véase el ejemplo del comerciante que propone el mismo Kant: según Wood, el comerciante podría abrigar una máxima que tuviese como thelos el aseguramiento, a través de un trato equitativo para con sus clientes, del logro de una buena reputación. Si uno pudiese preguntarle al comerciante ‘¿por qué haces eso?’, él podría respondernos: 'hago todo lo posible para asegurarme una buena reputación de comerciante honesto'. El objetivo de Wood es mostrar que las inclinaciones y el deber se entremezclan para dar lugar a la buena voluntad y que solo en virtud de ello las inclinaciones pueden cobrar merecimiento (Wood 1999: 23). No obstante, al mismo tiempo que se realza esta 'cooperación motivacional', se dificulta el reconocimiento de la buena voluntad, lo que hace que se le acuse a Wood de prestar oídos sordos a la cuestión de la autodeterminación moral (Pippin 2000: 244-245).

El asunto es que Wood parte de la idea de que la racionalidad kantiana es "la facultad de los principios de la acción", algo que aún los escépticos y naturalistas no pueden negar: que la posibilidad de las acciones no morales también depende del 'deseo de independencia', y de la necesidad de fundar las acciones en razones. De ahí que Wood entienda que en el caso de los imperativos hipotéticos, la libertad del agente se expresa mediante un principio de 'adherencia' inherente al sentirse atraído hacia cierto objeto. En caso de desear X, cuyo mejor medio para ser alcanzado es Y, y siendo Y algo aversivo para el agente, Wood sostiene que este puede tomarse la libertad, y por tanto la obligación, de crear un deseo W por Y fundado en un principio subyacente de 'adherencia' (Wood 1999: 52). Wood sostiene que las inclinaciones serán móviles de acción 'si y sólo si' son incorporadas a la máxima, esto es, consideradas como portadoras de razón, o autoridad suficiente como para orientar nuestra acción. De este modo, la decisión, en cuanto que expresión de la buena voluntad, se encontraría en la elección de los ‘bienes objetivos' como fines (Wood 1999: 128-129).

Esta teoría de la acción moral encamina a Wood a sostener la tesis principal de que la razón es directamente práctica en los casos no morales, lo que desentierra la existencia de un 'valor sustantivo' subyacente a toda la ética kantiana, explícita en la humanidad o 'capacidad racional de establecer fines'. Para el Kant de Wood, la vida moral consistiría en un conjunto indeterminado de expresiones de respeto, y evitación del irrespeto, hacia esta capacidad. Por ello es tan importante para Wood aprovechar el significado de esta 'capacidad racional'. Su convicción es la de que existe un principio de 'adherencia' fundamental y superior, que constituye una especie de 'bien objetivo', y que mueve al sujeto a perseguir aquello que considere valioso. Así es que Wood intenta dar un paso en la defensa de que, aún en contra de los posicionamientos de Kant, es posible determinar un estilo de vida buena como un 'bien objetivo' para nuestra voluntad.

Pero esta interpretación de Wood no deja de lado la moralidad, puesto que su tesis intenta demostrar que la moralidad y cierto valor substantivo se encuentran inextricablemente enlazados. Para ello nos llama la atención acerca de que tras la presentación de las dos primeras formulaciones del IC, Kant no explicita a cuál de ellas han de adecuarse las máximas, razón por la cual se pregunta sobre el significado de "adecuarse a la voluntad de un ser racional" (Wood 1999: 81). El sólo IC no nos brinda los elementos suficientes como para detectar por qué tal o cual ley debería ser buscada por nuestra voluntad. Sobre este asunto Wood arguye que el "worth of humanity provides us with an overriding reason grounding objective principles or categorical imperatives that is not dependent on our empirical desires but proceeds solely from our own rational faculties" (Wood 1999: 77). Según él, necesitamos este recurso reflexivo para poder completar la normatividad inherente a las formulaciones de la Universalidad y de la Naturaleza, por lo que el principio de la moralidad kantiana sería al mismo tiempo 'categórico' y un 'valor objetivo'. Esta combinación implica abandonar la idea 
de que tanto la primera como la segunda formulación ofrecen recursos suficientes para la deliberación moral (Wood 1999: 97), y aventurarse a defender la idea de que estas no constituyen nada más que versiones incompletas y preliminares de las fórmulas de la humanidad cual fin en sí mismo, de la autonomía y del reino de los fines, entendidas como 'valores objetivos'.

Este aventurarse a defender la idea de que la fórmula de la humanidad abriga un mandato categórico y un bien objetivo, constituye la estrategia distintiva del kantismo de Wood, y encuentra su evidencia textual en GMS 428: "Suponiendo que hubiese algo cuya existencia en sí misma posea un valor absoluto, algo como fin en sí mismo pudiera ser un fundamento de leyes bien definidas, ahí es donde únicamente se hallaría el fundamento de un posible imperativo categórico, esto es, de una ley práctica".

No obstante, si por un lado tenemos en cuenta que el análisis del concepto de una acción exige atender al fin perseguido, y por otro, que una acción moral requiere de un fin en sí mismo cuyo valor sea inestimable, ¿cómo puede Kant demostrar que 'exista' algo de tal valor, y conectarlo con nuestro deber de respetarle? Según Wood, la 'humanidad' es la respuesta kantianamente disponible para la primera pregunta, entendida como "la capacidad racional para establecer fines", mientras la llave argumental para responder la segunda recaería en una "inference from the objective goodness of the end to the unconditionally objective goodness of the capacity to set the end" (GMS 127).

El argumento que ofrece Wood para demostrar la objetividad del valor absoluto inherente a nuestra capacidad racional de establecer fines es una variante del argumento de regresión hacia el infinito que ya había defendido Korsgaard, y que abordaré más adelante. El argumento puede ser reconstruido en tres pasos: a) los objetos son deseados, buscados, y hacia ellos nos inclinamos en virtud de que previamente son envestidos por cierta bondad mediante nuestra racionalidad. Así es que la razón sería la fuente de valor no moral de todos los objetos; b) sin embargo, la razón, siendo la fuente de valor de lo demás, no puede atribuirse valor a sí mismo de igual modo en virtud de que en principio, no es una cosa, sino una capacidad que sólo percibimos mediante su atribución de valor; c) en consecuencia, la racionalidad no constituye un valor sin más, sino un valor inestimable, un valor, al decir de Kant, sin 'medida equivalente'. Esto es suficiente como para que Wood concluya que Kant "holds that the objectivity of the will's prescriptions comes from the rational capacity to set ends having objective value" (GMS 129).

\subsection{El Kant realista de Oliver Sensen}

Del realismo de Sensen me gustaría reconstruir aquí uno de sus argumentos más distinguidos y solventes, acerca del cual no estoy completamente seguro de si ha sido recibido con justicia en las discusiones neokantianas. Como es bien sabido, el realismo de Sensen representa una de las versiones neokantianas más difíciles de golpear en razón de que su reconstrucción de los textos kantianos es muy cuidadosa e iluminadora. En esta oportunidad, me gustaría detenerme en la reconstrucción que Sensen ha desarrollado acerca de la idea de 'valor interno' (inner value) de Kant, conectando de este modo la KrV, GMS y KpV.

Dentro del nudo de si Kant es realista o constructivista, Sensen sostiene que una forma prometedora de resolver la discusión consiste en asumir que el punto 'arquimédico' de la fundamentación normativa recae en la sola idea de libertad, pero sin reconocer en ella un valor axiológico sino una ratio essendi. En esta línea, Sensen ofrece una lectura precisa de la idea de libertad kantiana que no la entiende como valor moral, sino más bien como un 'valor interno'. La reconstrucción muestra, en primer lugar, que en ningún momento acude Kant a un realismo axiológico, sea moral o no moral, para fundar la validez moral del IC, sino que por el contrario lo funda en la sola idea de libertad:

el que la razón no pueda hacer concebible una ley práctica incondicionada (como ha de serlo el imperativo categórico) conforme a su necesidad absoluta, no es algo que suponga una censura para nuestra deducción del principio supremo de la moralidad, sino más bien un reproche que habría de hacerse a la razón humana en general; el hecho de que no quiera hacer esto mediante una condición, o sea, por medio de algún interés colocado como fundamento, es algo que no puede serle afeado, porque entonces no sería una ley moral, esto es, una ley suprema de la libertad (GMS 463) 
$\mathrm{Y}$ en segundo lugar, Sensen también intenta mostrar que la idea de libertad no constituye un valor moral, sino más bien un 'valor absoluto' que ciertamente sirve como fundamento de lo moral.

Si atendemos a lo que Kant entiende como 'intrínsecamente bueno' podemos recordar sus palabras acerca de cómo debe concebirse la buena voluntad: como algo que "pueda ser tenido por bueno sin restricción alguna", cual brillo de una joya. En verdad, Kant no se refiere a la buena voluntad como una joya, sino que se detiene en su brillo, algo que percibimos pero que no comprendemos en el instante que surge, con lo que busca ilustrar "esta idea del valor absoluto de la simple voluntad". Siguiendo de cerca las reflexiones de Sensen, podemos ver que la buena voluntad es un valor absoluto, más en ningún lugar Kant se refiere a ella como un valor moral, puesto que en ningún lugar Kant justifica la homologación que las lecturas neokantianas tradicionales han asumido aproblemáticamente entre lo que es un valor en sí mismo y lo que es un valor moral.

Recordando que Kant comparte que "[1]a palabra absoluto se usa ahora con frecuencia para indicar simplemente que se atiende a algo en el sentido de que pertenece a una cosa en sí misma, algo que, en consecuencia, posee validez intrínsecamente" ( $\mathrm{KrV}$ A 324/B 381) ${ }^{8}$, podemos observar que 'absoluto' e 'intrínseco' refieren a dos tipos de juicios que en común tienen el abstraer al objeto de todas sus determinaciones (Sensen 2009: 273; 2011: cap. 1). Justamente, es en estos términos que Kant comienza el primer capítulo de la Fundamentación enfatizando que lo intrínsecamente valioso de la buena voluntad consiste en su sólo 'principio global del obrar', concepto al cual sólo se accede por medio de la abstracción que debemos realizar al contemplar un concepto de voluntad ausente de determinaciones. Si esta conexión es acertada, el valor intrínseco de la buena voluntad no recae en su valor moral, sino más bien en su condición de valor incondicionado:

La buena voluntad no es tal por lo que produzca o logre, ni por su idoneidad para conseguir un fin propuesto, siendo su querer lo único que la hace buena de suyo y, considerada en sí misma, resulta sin comparación alguna mucho más estimable que todo cuanto merced a ella pudiera verse materializado a favor de alguna inclinación e incluso, si se quiere, del compendio de todas ellas (GMS 394) ${ }^{9}$.

De este modo, parece sostenible la tesis de que la idea de libertad, en tanto valor absoluto o intrínseco no mantiene necesariamente una connotación moral. Si esto es así, y recordamos que páginas atrás también se ha afirmado que el IC, y por ende, el factum de la razón, nos revela la problemática 'realidad' de la idea de libertad ¿debemos concluir que la obligación inherente al deber no es moral?

Sensen piensa que para Kant, y su época, bastaba con referirse a la idea de valor absoluto, o incondicionado, para lograr conectar con éxito los usos teórico y práctico de la razón, o en otras palabras, para no continuar con la fundamentación del deber. Así es que también piensa que, a la luz de los contemporáneos desafíos y embates ofrecidos por los escépticos y naturalistas, es preciso trazar una argumentación acorde al pensamiento de Kant que trascienda el mero recurso argumental del valor absoluto. Un ejemplo de ello es su postura acerca de por qué hemos de respetar a los otros. El cognitivismo de Sensen es tan fuerte que incluso no necesita recurrir al valor del otro para encontrar allí razones. Él, sencilla y acertadamente, argumenta que "Kant does not ground the requirement to respect others on any value at all. Rather, one should respect others because it is commanded by the categorical imperative" (Sensen 2010: 103).

\subsection{Limitaciones del realismo neokantiano}

Con la presentación de estas dos lecturas realistas del kantismo caigo, nuevamente, en la injusticia de reunir todas sus tonalidades dentro de rudas esquematizaciones. Pero al igual que en IC, pretendo aquí esbozar las que a mi juicio representan sus principales limitaciones.

En el caso de Wood, en principio, podemos recoger su intento de mostrarnos cómo encajaría una atractiva teoría sustantiva del valor moral dentro de la arquitectónica kantiana. Sin

${ }^{8}$ Traducción de Pedro Ribas en la edición de Kant I, Madrid, Gredos, 2014.

${ }^{9}$ La cursiva ha sido agregada por el autor. Esta interpretación del 'valor intrínseco' es consistente con la definición que Kant ofrece de la dignidad (GMS 434) y el respeto (GMS 401, segunda nota al pie de Kant) 
embargo, al mismo tiempo que la exposición de Wood es clara en este sentido, también parece ser evidente en cuanto a su limitación, en particular, en lo dificultoso que resulta determinar la bondad objetiva, con normatividad incluida, desde un enfoque que no dispone de recursos capaces de establecer cuál valor objetivo es mejor que otro (Pippin 2000: 255-256). En virtud de ello, la relatividad de la determinación de la bondad objetiva inherente al 'para mí' hace que su versión del kantismo sea difícilmente atribuible al propio Kant; a menos que el objetivo de Wood no haya sido el de construir una interpretación fiel de Kant, sino el de ofrecer una interpretación kantiana acorde a las necesidades actuales; algo que podemos conceder, pero difícilmente encontrar en su texto.

Sin embargo, creo que tal ausencia de criterios normativos es una consecuencia de la persuasión que abriga su argumento por regresión al infinito en favor del valor de la humanidad. En lugar de defender la idea constructivista de que la racionalidad práctica constituye un valor absoluto en virtud de que ella se valoriza de tal modo, su argumento concluye que la razón es portadora de un valor pre-existente a su ejercicio, descubierto y utilizado como recurso durante la reflexión práctica (v.t. Hills 2008: 186). Lo que a simple vista nos lleva hacia una versión no cognitivista, y casi intuicionista, del kantismo.

Consecuencias similares podemos recoger de las investigaciones de Paul Guyer, quien recurre a un temprano ensayo de Kant para defender la tesis de que durante toda su vida, el filósofo de Königsberg habría tenido en mente que la idea de libertad, en tanto valor absoluto indemostrable, constituye la fuente última de la moralidad. De aquel ensayo de 1764, titulado Estudio sobre la claridad de los principios de la teología natural y de la moral, Guyer extrae el siguiente pasaje:

Only in our times has it begun to be understood that the faculty for representing the true is cognition, but that for sensing the good is feeling, and that these must not be confused with each other. Now just as there are unanalyzable concept of the true $(. .$.$) so there is also an unanalyzable feeling of the good$ (...) But if this (good) is simple, the judgement: this is good, is fully indemonstrable, and is an inmmediate effect of the consciousness of the feeling of pleasure with the representations of the object (...). Thus, if an action is inmmediately represented as good (...) then the necessity of this action is an indemonstrable material principle obligation (2: 299 ápud Guyer 2000: 130).

Si bien Guyer no cita un texto maduro de Kant en el que vuelva a aparecer este tipo de afirmaciones, se convence lo suficiente como para sostener la tesis de que Kant habría basado todo su programa de fundamentación moral en la sola e indemostrable idea de libertad. A sabiendas del cambio metodológico de la Fundamentación, esto es, el intento de Kant de abordar lo moral desde el 'sentido común', Guyer puede contentarse con analizar el inicio de su primer capítulo a la luz de la premisa de que "recognition and acknowledgment for the binding force of the fundamental principle of morality is readily available every normal human being" (Guyer 1998: 28).

Pero esta interpretación padece de algunas asperezas. La más importante de ellas es la siguiente: si es verdad que durante la Fundamentación Kant tuvo en mente la indemostrabilidad de la idea de libertad como fundamento de su programa moral, entonces ¿cómo es posible que esta sea tan fácil de ser reconocida y conocida intersubjetivamente? Afirmar que la moralidad se funda en una idea indemostrable pero accesible para todo ser humano común en pos de la mutua atribución de libertad, excede el campo del apriorismo kantiano, y la vuelve una cuestión empírica irresoluble, en razón de que, parafraseando las palabras de Kant, desde el punto de vista de un observador toda evidencia de mutua atribución de libertad es dudosa de abrigar una acción conforme al deber.

En líneas generales, el objetivo del realismo neokantiano parece claro: determinar cuál es el valor sustantivo subyacente a la ética kantiana para así poder saber en qué nos desviamos cuando no actuamos conforme a nuestra racionalidad práctica. Pero durante la persecución de este objetivo, Wood y Guyer aún nos dejan con profundas cuestiones sin resolver: a) ¿por qué tal capacidad racional de establecer fines (o idea de libertad) es digna de respeto?; b) ¿cuál es la conexión entre el valor absoluto de nuestra capacidad racional de establecer fines (o idea de libertad) y nuestro deber de respetarle?, y más importante; c) ¿qué recurso tenemos a mano para dirimir entre diferentes bondades objetivas, entre las nocivas y saludables, entre las mejores y las peores?, en otras palabras ¿cómo saber cuándo nos desviamos de estos valores absolutos? 
Por su lado, el caso de Sensen es bien diferente. En principio porque sus reconstrucciones asumen explícitamente el objetivo de elaborar la mejor interpretación del programa moral kantiano. Ciertamente, me ha llamado la atención que, al mismo tiempo que Sensen ha buscado elaborar la interpretación más fiel de Kant, ha logrado que este último se muestre más consistente que en las versiones neokantianas restantes. En otras palabras, parece casual que el Kant de Sensen sea, a mi juicio, uno de los neokantismos más sólidos de la contemporaneidad. Su idea exegéticamente elaborada de que la fundamentación de la moral kantiana se funda en una bicondicionalidad que comunica a la idea de libertad en un extremo con el IC del otro, resulta de las más esclarecedoras. No obstante, tengo alguna reserva acerca de su tesis del 'valor interno'.

Mi principal reserva nace también de forma exegética, puesto que en sus Lecciones de ética, Kant también atribuye un valor interno al entendimiento: "Estimamos aquello que detenta un valor intrínseco y amamos o sentimos afecto hacia lo que guarda relación con algo valioso; así, por ejemplo, el entendimiento posee un valor intrínseco sin considerar aquello a lo que se aplique" (V$\mathrm{Mo} /$ Collins 357$)^{10}$. Si bien no poseo toda la evidencia textual que me gustaría, este pasaje me es suficiente como para sospechar que Kant atribuía un valor interno a todo aquello que fuese una condición a priori del sujeto trascendental, en especial, porque estaría por fuera del espacio-tiempo como para poder ser sometido a valoraciones 'relativas'. Por añadidura, también tengo algunas reservas acerca de si el sólo 'valor interno' de la buena voluntad es suficiente como para volverle un valor moral, según lo sostiene Sensen ${ }^{11}$. No obstante, más importante son mis dudas acerca de si Sensen logra responder a la pregunta de cómo pueden, la idea de libertad y el IC, conectar con el agente, esto es, cómo es que le presionan normativamente.

Si Sensen está en lo cierto, la idea de libertad opera como condición de posibilidad del IC, pero ¿cómo es esto posible? Pues, como ratio essendi, lo que en otras palabras podríamos denominar 'razón de ser' o 'sentido'. Esto no desembocaría en un realismo no cognitivista puesto que el IC constituye la ratio cognoscendi de la idea de libertad, esto es, el modo en el cual podemos acceder a ella. Pero me temo que esta conexión deja en el vacío al sujeto, esto es, a la constricción de la propia voluntad que este siente mediante el deber, y la apertura de la posibilidad que la libertad le cede: el cumplirla o no. Como nota Hegel en $\S 14$ y $\S 15$ de su Rechtsphilosophie, si la libertad posibilita el deber moral, y en tanto 'deber', supone la posibilidad de que la acción no sea como 'debe', entonces es el libre arbitrio un momento judicativo superior que radica en el sujeto, en el yo. A pesar de que la bicondicionalidad 'libertad-IC' que reconstruye Sensen constituya un aporte significativo, opino que aún no se ha dilucidado cómo es que el sujeto, y su libre arbitrio, resuelven finalmente su relación con los extremos de tal bicondicionalidad. Para abordar este asunto de la relación entre el sujeto y la obligación moral resulta imperioso detenernos en la influyente tesis de la identidad práctica de Korsgaard.

\section{El neokantismo de Christine Korsgaard}

Korsgaard comparte con Kant la convicción de que el problema de la normatividad parece estar íntimamente conectado con la capacidad reflexiva del agente. Para mostrar esta conexión, en Presunto comienzo de la Historia Humana Kant nos invita a imaginar un escenario dentro del cual el desarrollo humano sólo le permite al hombre orientar su acción acorde al instinto. En tal estado podríamos saber, por ejemplo, qué alimentos debemos evitar con sólo olerlos, puesto que el sentido del olfato por sí mismo proporciona razón suficiente para evitar la comida, lo que muestra que sin reflexión no parece existir brecha entre el estímulo y la respuesta a la pregunta normativa que surge. Sin embargo, nuestra relación con el mundo sufre un radical e irreversible cambio cuando descubrimos dentro de nosotros una capacidad activa para elegir el curso de nuestro comportamiento: "[El hombre] Se encontró, por así decirlo, al borde de un abismo, pues entre los objetos particulares de sus deseos -que hasta ese entonces había consignado el instinto- se abría ante él una nueva infinitud de deseos cuya elección le sumía en la más absoluta perplejidad” (MAM 112).

\footnotetext{
${ }^{10}$ Las traducciones de V-Mo/Collins que recojo aquí son las de Roberto R. Aramayo y Concha Roldán Pandero, de la edición de Barcelona, Crítica, 2009.

${ }^{11}$ En la sección 4.3 abordaré en detalle este problema.
} 
Tras el surgimiento de la reflexión el hombre no pierde su capacidad de oler la comida, ni este olor deja de abrigar una razón para evitarla, aunque sí deja de ser, esta razón, suficiente por sí misma. Por medio de la reflexión el sujeto llega a ser libre de ignorar los datos de los sentidos, o de buscar mejores razones más allá de sí. Sin embargo, renunciar a la inmediatez y autosuficiencia de las razones de los deseos desorienta al hombre al sumergirlo en una infinidad de posibles cursos de acción, angustiándole, y moviéndole a preguntarse por la posibilidad de recuperar, o al menos mantener, alguna certeza práctica semejante a la del hombre puramente natural.

Como lo entiende Kant, el mismo acto de someter a revisión aquellas razones inherentes a los deseos que se nos presentan a la consciencia prueba que estos deseos no poseen la suficiente autoridad como para orientar por sí solos nuestra acción. Sin embargo, podemos descubrir razones de autoridad, y por lo tanto, llevar el proceso de reflexión hacia una exitosa conclusión en la medida que seamos capaces de elaborar un punto desde el cual fundarla, aún sin saber cuál es este punto. Pero el problema que se nos presenta aquí es que tal reflexión no parece tener, a simple vista, un punto final, sino que la misma puede llevarse hasta el infinito una vez que exige la fundamentación de sus razones en otras razones. Y es justamente con motivo de atender este problema que las reflexiones de Christine Korsgaard buscan defender la tesis de que tal punto final lo constituye cierta identidad práctica, que enlaza a la consciencia y sus procesos reflexivos con los principios, reglas y razones que le presionan normativamente.

Según Korsgaard, la identidad práctica no es algo que se nos dé desde fuera del proceso de reflexión, sino que sólo puede surgir desde el interior de ella. Es en la fundamentación racional de un contenido particular de la conciencia que me revelo a mí mismo como un sujeto que irrenunciablemente debe elegir (Korsgaard 2000: 129). No puedo dejar de reconocer mis opciones, y de forma más fundamental, las razones que soportan las decisiones como expresión del yo que se manifiesta en toda reflexión (Korsgaard 2000:133). El punto neurálgico que Korsgaard desea instaurar aquí recae en la tesis de que no se puede fundar cualquier otra identidad práctica: me resultaría imposible fundar con razones tal o cual identidad práctica, sea esta mi identidad como hijo o hermano, profesor universitario o futbolista. Ciertamente puedo deliberar sobre lo que requieren estas identidades de mí, así como también acerca de si debo seguir actuando según las diferentes maneras que las sustentan, pero en modo alguno puedo ofrecer una fundamentación última de la necesidad de tener una identidad práctica. El sólo hecho de intentar buscar este trasfondo nos llevaría hacia un acto de reflexión al que por sí mismo le sería inherente el tipo de identidad práctica que se intenta fundar. En consecuencia, la reflexión alcanza su punto final en la identidad práctica, y es por eso que Korsgaard se muestra convencida de que sólo una identidad práctica de estas características es capaz de fundar las razones últimas de toda acción.

Korsgaard sostiene que la identidad práctica opera como fuente de nuestras obligaciones a través de lo que denomina 'rechazo reflexivo'. Nos experimentamos como sujetos obligados cuando, tras reflexionar sobre un posible curso de acción, alcanzamos la conclusión de que la acción es incompatible con el tipo de persona presente en un yo que se es. Para ilustrar este punto piénsese que mi identidad práctica sea el ser juez penal de un tribunal, de quien se espera que emita juicios fundados en la legislación vigente para determinar la resolución de los procesos, las penas y sus cuantías. Supóngase que ante una inmensa cantidad de casos a atender, me surge la idea de someter las resoluciones a sorteo en un bolillero, incluyendo las penas y sus cuantías, a modo de aligerar los procesos y obtener de esta forma menos trabajo. Desde el punto de vista de la identidad práctica, la idea de someter las resoluciones de los procesos al azar, considerada en tanto posible curso de acción, 'contradiría' la integridad de mi identidad práctica, destruyendo de esta forma mi yo en tanto juez que juzga y dictamina procesos fundados en una legislación positiva vigente. De esto se concluye que tal rechazo reflexivo se convierte en la fuente de normatividad de mis obligaciones.

La obligación es una cuestión de lo que Korsgaard llama 'integridad'. El acto de reflexión presenta un yo que debe ser una ley para sí mismo, es decir, que debe ser capaz de identificarse con los principios de sus propias decisiones. Para llevar adelante acciones que no puedo apoyar sobre razones es necesario que previamente tampoco exista una ley para mí. Si me identifico, por ejemplo, con los tipos de principios apropiados para la consciencia de un juez penal, no puedo, al mismo tiempo, identificarme con la idea de someter todas las resoluciones judiciales de los procesos al azar. 
Tal acto me pondría en contradicción conmigo mismo, violentando la integridad que la reflexión exige de un 'yo' (Korsgaard 2000: 130-131).

De acuerdo a las reflexiones de Korsgaard, la obligación tiene un dominio sobre nosotros sólo a través de nuestras identidades prácticas. Esto es explicitado cuando escribe que "[u]na obligación siempre toma la forma de reacción contra una amenaza de pérdida de identidad" (Korsgaard 2000: 131). La necesidad de mantener la integridad de nuestras identidades prácticas constituye el elemento de restricción esencial para la experiencia de la obligación del deber. Este punto puede ser ilustrado con aquel ejemplo que Kant nos ofrece en $\mathrm{KpV} 28$, el cual trata sobre la inmoralidad de la acción de apropiarse del depósito de un fallecido. En este caso no podemos encontrar algún tipo de restricción externa, sea este el miedo a la persecución, o a ser mal vistos por la sociedad, en virtud de que en la descripción del problema nadie más que yo sabe acerca del depósito. Sin embargo, podemos encontrar, al menos vagamente, una especie de coacción moral interna. Nuestra filósofa podría describir este sentimiento de restricción como el reconocimiento de la incompatibilidad entre la acción de apropiación del depósito y mi identidad práctica en tanto asegurador de depósitos, pues es evidente que el acto de mantener el depósito 'amenaza' mi identidad en tanto los demás dejarían de realizar depósitos. El perder la identidad, y más fundamentalmente, la integridad de la propia identidad, significaría 'algo peor' que la muerte para el agente que la porta, y en virtud de ello, aquella sensación de restricción inherente a la experiencia del deber tiene su origen en lo que es esencialmente una amenaza de muerte (Korsgaard 2000: 131)

Finalmente, Korsgaard se esfuerza por aumentar el alcance de la tesis sobre la necesidad de la identidad práctica a través de un argumento trascendental que, en particular, agrega a lo anterior su interés por demostrar la apodicticidad específica de la identidad práctica del agente en tanto ser humano, como un tipo de identidad práctica 'profunda' no contingente.

El primer paso de este argumento se apoya en la idea, establecida anteriormente, de que debemos tener razones para actuar. Los impulsos y deseos no son suficientes por sí solos para determinar las voluntades de seres como nosotros. Esas razones para la acción, deben lograr el 'éxito reflexivo' al compatibilizar con la integridad de nuestras identidades prácticas en tanto hijos, hermanos o jueces penales. Sin embargo, estas identidades prácticas son contingentes, y como tales, son incapaces de poner fin al proceso de reflexión, llevándolo hacia el infinito. Esto resulta evidente una vez que podemos acordar que la resolución azarosa de los procesos judiciales a través del sorteo destruye la integridad de la identidad práctica de un juez penal; pero aun así podemos preguntarnos: ¿por qué debería tener yo esa identidad y no otra? Esta pregunta se mantiene frente a las identidades prácticas y parece imposibilitar el punto final de la reflexión necesaria y suficiente capaz de hacer posible la acción racional, esto es, la necesidad de saber por qué debemos tener 'tales o cuales' identidades prácticas, aunque experimentemos la necesidad de tener una. Es aquí donde el argumento de Korsgaard busca volverse trascendental: a partir de su convicción respecto de que se requiere de razón para luego conferir valor a nuestros actos, Korsgaard observa que esas razones no reposan principalmente sobre una identidad práctica contingente sino más bien sobre una más 'profunda' presente en todos los seres humanos en tanto seres humanos. Esta identidad práctica profunda es encontrada por nuestra filósofa en la ley práctica de la humanidad formulada por Kant en su Fundamentación. Ser un ser humano significa ser la clase de ser que necesita razones para actuar, y en consecuencia, que debe poseer una identidad práctica que le permita identificarse a sí mismo a través de sus mandatos elaborados. Si constituye un hecho racional el que podamos constatar, a través de la reflexión, la consciencia de una obligación por asentir o no asentir racionalmente nuestros deseos e impulsos, entonces podemos afirmar que tal constatación sólo puede darse en la medida en que exista una identificación con aquella necesidad. De esto se concluye que la experiencia de presión moral, posibilitada por la identificación con la ley, constituye una característica constitutiva y exclusiva del ser humano. Así es que la identidad práctica profunda, la humana, y la obligación de la acción racional que le es inherente, son "ineludibles y omnipresentes" (Korsgaard 2000: 154), tanto frente a uno en cuanto que fin en sí mismo como frente a los demás en cuanto que reino de los fines.

\subsection{Limitaciones del neokantismo de Korsgaard}


Existe una extensa bibliografía crítica sobre la tesis de la identidad práctica de Korsgaard. Pero amén de no restarle importancia al resto de la discusión, me concentraré aquí en las dos objeciones que entiendo más acertadas: la primera de ellas pone en tela de juicio el status teorético de la identidad práctica, en particular, en su relación con la ley moral, mientras la segunda atañe más específicamente al foco de nuestro trabajo, a saber, las implicaciones realistas de una pretendida tesis radicalmente constructivista.

i) Entrando con cierto detalle en el argumento central que Korsgaard ofrece para demostrar que la identidad práctica constituye la fuente última de la normatividad, podemos encontrar afirmaciones controvertidas acerca de si el sujeto crea la ley, o la ley crea el sujeto. Estas afirmaciones, que se encuentran especialmente en las respuestas que Korsgaard presenta a las objeciones de Gerald Cohen, intentan dilucidar el tipo de autoridad que, en su opinión, el agente muestra frente a la ley.

Durante sus comentarios, Cohen presenta dudas acerca del alcance normativo de la identidad práctica korsgaardiana, pues es razonable pensar que si el sujeto creador de la ley muestra una autoridad normativa frente a ella por ser simplemente su creador, esto también implicaría que él tendría la misma autoridad para no cumplir tal ley. Cohen ilustra este caso con el monarca hobbesiano, quien crea leyes generales con la suficiente autoridad normativa sobre ellas como para no cumplirlas, sin que esto conlleve un daño para su identidad (Cohen 2000). La respuesta que Korsgaard ofrece a esta objeción tiene dos partes, de alguna manera entrelazadas: en primer lugar defiende la tesis de que mientras el monarca hobbesiano no crea la ley con un margen normativo de comprensión lo suficientemente general como para incluirse a sí mismo en él, la ley moral kantiana sí exige incluir al creador de la ley, pues de otro modo no calificaría como ley moral. Sin embargo, lejos de mostrar que la ley moral es sentida como una ley de la naturaleza, Korsgaard asiente respecto de la posibilidad de no cumplir la norma, puesto que en la posibilidad de no cumplirla recae la diferencia entre la buena voluntad humana y la 'voluntad santa'.

Este último asentimiento de la filósofa estadounidense resulta algo extraño, en la medida en que, durante su tercera conferencia, había insistido en que la violación del deber moral significaría para el sujeto 'algo peor que la muerte'. Pero la coherencia interna que mantienen sus afirmaciones acerca de la identidad práctica y su asentimiento de que es posible violar la ley moral sin destruir la subjetividad, es fuertemente subsidiaria de su particular concepción acerca de la relación mantenida entre la ley y la identidad práctica:

Me doy cuenta de que hay cierto tono de paradoja en lo que acabo de decir. ¿Quién (...) es el yo aparentemente efímero que tiene que unificarse a sí mismo en un agente o carácter que pueda persistir a lo largo de un conjunto de ocasiones que sean similares de manera pertinente, y por qué, si es de verdad efímero, tiene que hacerlo? La respuesta es que el yo efímero es el yo que reflexiona, el yo que ve su impulso desde cierta distancia reflexiva. Y la razón por la que tiene que unificarse en un agente que pueda persistir a lo largo de una serie de ocasiones que sean similares de manera pertinente (...) es más bien que la visión de sí mismo como activo conlleva ahora esencialmente una proyección de sí mismo en otras ocasiones (Korsgaard 2000: 282)

La respuesta de Korsgaard se sostiene sobre la idea de que es la ley moral la que crea la identidad práctica, pues la identidad práctica se construiría en la medida en que el yo pensante pueda elaborar la ley, y afectar al 'yo' actuante de algún modo no del todo claro ${ }^{12}$. Pero el problema aquí parece ser inherente al lenguaje kantiano empleado. En primer lugar, Korsgaard no puede sostener que la identidad práctica subyace en la formulación de la ley, para luego reconocerla como propia, pues, además de coquetear con una petitio principi, sería esta una tesis realista en sentido fuerte, algo con lo cual no simpatiza demasiado. Y en segundo lugar, Korsgaard parece omitir por completo que el empleo de los términos 'yo pensante' y 'yo actuante' está preñado del insoluble problema de la comunicación entre los mundos nouménico y fenoménico, muy presente para el mismo Kant. Korsgaard interpreta el factum de la razón como una evidencia de la comunicación entre estos yoes

12 "Los principios morales, para plantearlo en un lenguaje no platónico, son lo que da una voluntad al alma considerada como una entidad unificada (...) Como Paltón, creo que ni las almas humanas ni las comunidades humanas se pueden mantener juntas, ni pueden ser unificadas, y por lo tanto no pueden ser realmente, a menos que sean (por lo menos en alguna medida) Repúblicas, y se sometan al gobierno de la ley. Y por eso pienso que la libertad y la autonomía requieren que nuestra voluntad se rija por una ley universal" (Korsgaard 2000: 284). 
pensante y actuante, lo cual no necesariamente mostraría la posibilidad de la identidad práctica; y en caso de que lo haga, no lo sería de una identidad práctica construida, sino realista ${ }^{13}$. A efectos de establecer cierta reserva frente a esta argumentación, supongamos que, como dice Korgsaard, el 'yo' pensante formula una máxima que puede ser querida como ley universal. Según Kant, el factum de la razón nos manifiesta la presión del deber inherente a tal máxima en tanto que uno es un 'yo' actuante. La pregunta es: ¿la identidad práctica es aquí construida, o por el contrario ya estaba presente a modo de condición de posibilidad del factum de la razón? Aquí Korsgaard nos sugiere que la identidad práctica es producto de la unificación de los 'yoes' lograda por la ley moral. Pero si esto es así, aún quedaría sin explicación el efecto primitivo del factum en virtud de que ya no sería la identidad práctica la que posibilitaría el factum, pues aquella no existía antes de este. Uno puede pensar que existe una identificación o comunicación previa entre los 'yoes' pensante y actuante a modo de condición de posibilidad del factum, algo que en palabras de Kant sería un misterio para el entendimiento humano, pero que Korsgaard no admitiría. Como sea, si el factum precede a la identidad práctica, parecen aún faltar argumentos que den cuenta del origen de la normatividad primitiva del factum mismo, lo que pondría en tela de juicio la pretensión korsgaardiana de encontrar en su defendida identidad práctica la fuente última de la normatividad moral (Lueck 2009).

En virtud de las anteriores observaciones, podemos augurar dos posibles formas de interpretar su tesis: a) como defensa de la idea de que la identidad práctica es presupuesta a la hora de experimentar el factum de la razón, en virtud de lo cual, además de asumir cierto tipo de realismo, parecería no agregar nada más que una condición de posibilidad de tal factum, sumamente problemática a la luz de la conocida incomunicabilidad entre los mundos fenoménico y nouménico; b) como defensa de la idea de que, efectivamente, tal identidad práctica es construida a partir del factum del deber moral, lo cual nos llevaría a no depositar en tal identidad las fuentes de la normatividad, sino, más bien, en el factum mismo.

ii) Como puede suponerse, la segunda objeción nace como consecuencia de la primera, hundiendo sus raíces en la discusión acerca de la teoría del valor subyacente en la ética kantiana. En rasgos generales, sobre este punto Korsgaard se apercibe una constructivista radical ${ }^{14}$. Pero como hemos visto, en el corazón de las propuestas constructivistas los realistas golpean en un punto ciego, lo que, en el caso de Korsgaard, iría en contra de su concepción del hombre en cuanto que fin en sí mismo, único fin moral en su opinión.

Siguiendo las reflexiones de Korsgaard, el valor moral inherente al ser humano en tanto tal, es dado o deducido a partir de la estructura reflexiva de su consciencia, la única capaz de fundar y validar las acciones en razones. Sin embargo, si bien los realistas podrían aceptar la premisa de que los valores morales y no morales son construidos o justificados vía buena voluntad, o en términos de Korsgaard, vía rechazo reflexivo, los realistas no aceptarían el 'tipo' de conclusión que de allí se pretende extraer, a saber, que la misma buena voluntad, o en palabras de Korsgaard, el ser portador de reflexión, sea un valor en sí mismo. He aquí el tradicional problema de los límites de la autojustificación de la razón que ya se ha mencionado: del hecho de que $\mathrm{R}$ sea la fuente de valoración de las cosas no puede concluirse que R sea un 'valor en sí' mismo.

Como hemos visto, realistas como Wood sostienen que esta conclusión revela un valor objetivo inherente y preexistente al acto reflexivo, que es 'descubierto' por este. Pero los constructivistas optan por insistir en la vía de mostrar que la razón se autovalora a sí misma, y que he allí la fuente de su valor incondicional, lo cual por cierto, se acerca alarmantemente hacia un solipsismo que vuelve teoréticamente insulsa a la capacidad racional misma de valorar y elaborar fines ${ }^{15}$.

Este conjunto de reservas acerca del éxito de las reflexiones de Korsgaard en torno al problema de las fuentes de la normatividad nos lleva, en principio, a no dar por saldada la discusión. Con este espíritu es que atribuyo a las reflexiones de Korsgaard un gran valor, aunque tal valor no sea

${ }^{13}$ William J. FitzPatrick (2005) ha identificado ambigüedades realistas y constructivistas similares en varios textos de Korsgaard.

${ }^{14}$ Aunque sus declaraciones de 'realista procedimental' nos confundan bastante (Korsgaard 2000: 3.5, 3.6).

${ }^{15} \mathrm{El}$ supuesto de que la autovaloración racional es la fuente de toda valoración moral y no moral es determinante en los intentos de argumentación trascendental de Korsgaard (2000: 157). 
iluminado desde la óptica de nuestra filósofa, sino más bien desde una óptica más modesta. Las evidentes ambivalencias (y no les llamo contradicciones) inherentes a la tesis de la identidad práctica de Korsgaard iluminan lo que pretendo mostrar a continuación: una vez abordada profundamente la ética kantiana desde los prismas constructivistas y realistas, podrá notarse que resulta imposible clasificarla en los solos y exclusivos términos proyeccionistas o detectivistas. Así es que en lo que sigue me abocaré a defender la tesis de que, o bien la singular ética de Kant es constructivista y realista al mismo tiempo, o bien no es ninguna de ambas.

\section{Bases para una lectura constitutivista de la ética kantiana}

En lo precedente he reconstruido las coordenadas más distinguidas de la contemporánea discusión kantiana acerca de las fuentes de la normatividad, y su teoría del valor subyacente. Tal discusión nos deja con la sensación de que no resulta del todo evidente el que pueda leerse a Kant bajo exclusivos lentes constructivistas o realistas. Motivado en parte por esta sensación, en lo que sigue argumentaré que la originalidad de la ética kantiana escapa a las rígidas determinaciones proyeccionistas y detectivistas al asumir un modelo constitutivista respecto de las fuentes de la normatividad. La ética kantiana puede ser abordada desde los prismas proyeccionistas y detectivistas porque es proyeccionista y realista, pero al mismo tiempo, y de forma insorteable. Esta tesis acerca de la indisociabilidad entre el proyeccionismo y detectivismo es la que dará lugar al modelo que aquí denomino constitutivista, el cual, en pocas palabras, entiende que las fuentes de la normatividad y el valor, son una construcción reflexiva del agente que implica, al mismo tiempo, y de forma performativa, asumir la libertad como un valor absoluto.

La principal llave argumental que utilizaré en mi razonamiento será la de la contradicción performativa, defendiendo la idea de que este recurso argumental puede ayudarnos a comprender el tipo de fundamentación moral implementado por Kant. Una vez asentado esto con cierta consistencia, podré mostrar por qué el modelo constitutivista representa el mejor camino para reconstruir la postura kantiana acerca de las fuentes de la normatividad y el valor.

5.1. La idea de libertad, el Imperativo Categórico, y la identidad práctica, conectadas mediante la contradicción performativa

Como lo he expresado durante el desarrollo de este trabajo, estoy convencido de que la bicondicionalidad 'libertad/IC' reconstruida por Sensen, y la tesis sobre la identidad práctica de Korsgaard, constituyen valiosos aportes para la discusión acerca de las fuentes de la normatividad. Sin embargo, habiendo señalado ya lo que entiendo como sus limitaciones, me dispondré a argumentar que es posible superar sus respectivas debilidades conectándolas mediante el recurso de la contradicción performativa. En lo que sigue, presentaré mi argumentación en cuatro instancias.

i) Siguiendo a Korsgaard, Kant parece tener en mente la convicción de que sólo por medio de la reflexión es que podemos construir y permitir la presión del deber sobre nosotros mismos, puesto que nos identificamos con la ley, y por tanto, nos reconocemos en ella como su creador. Sin embargo, a diferencia de Korsgaard, no creo que esta identidad práctica que surge en el corazón de la estructura reflexiva de la conciencia 'tan sólo' se reconozca en la ley, sino que hemos de agregar que al mismo tiempo se reconoce a sí misma como libre.

Mi sugerencia es que la bicondicionalidad identificada por Sensen sólo puede nacer al abrigo de la estructura reflexiva de la consciencia korsgaardiana, puesto que tal bicondicionalidad será capaz de presionar normativamente al sujeto 'si y sólo si' este puede reconocerse tanto en la ley, como en su calidad de libre. Cuando el agente se identifica con la ley en razón de que se asume como su creador, ha de asumir al mismo tiempo que durante su creación ha sido libre, de lo contrario la presión del deber sería considerada heterónoma. Así es que la identidad práctica operaría como un puente tríadico entre el agente, la ley, y la idea de libertad del siguiente modo: la idea de libertad ha de ser entendida como la ratio essendi de la ley moral, a la cual accedo en la medida en que elaboro la ley; ley que, finalmente, representa algo 'para mí' en la medida en que me identifico con ella. 
De esta forma podemos abordar lo que Sensen pasa por alto, esto es, la explicación acerca de cómo es posible que el deber afecte al agente. Por añadidura, la introducción de la idea de libertad completa lo que Korsgaard omite al enfocarse casi exclusivamente en la ley moral. Razón por la cual no creo que sea posible postular alguno de estos componentes como prioritario frente a los demás, y por ello ha de insistirse en que los tres surgen al mismo tiempo.

Para desarrollar tal tesis, sucintamente enunciada hasta el momento, he de presentar argumentaciones favorables en torno a las siguientes cuestiones: 1) ¿cómo es posible el surgimiento simultáneo de estos tres elementos?; 2) ¿en qué posición deja esta tesis a Kant respecto del valor: es constructivista o realista?; 3) ¿de qué evidencia textual dispone esta tesis?

ii) Para abordar la primera pregunta resulta sumamente útil recurrir al argumento de la contradicción performativa.

Como es bien sabido, en su Metafísica Aristóteles desarrolla un tipo de argumentación de lo más ingenioso, comúnmente conocida como 'contradicción performativa'. Con el objetivo de refutar el escepticismo gnoseológico, en I 4 (1008b12-25) Aristóteles pregunta por los estándares de justificación epistémica que subyacen a la objeción escéptica: si bien el escéptico niega la posibilidad de todo conocimiento del mundo, en su práctica cotidiana se orienta pre-reflexivamente por distinciones como dulce, amargo, opinión profesional, opinión desinformada, y demás, sin una justificación particular. De este modo, se pone al descubierto que la duda escéptica necesita suponer un conjunto de conocimientos del mundo para luego ponerlos en duda, lo que implica una acción contradictoria.

Para nuestros intereses, es por demás razonable recurrir a este argumento en la medida en que podamos identificarla en la base de lo que Korsgaard entiende por 'estructura reflexiva de la consciencia'. Mi sugerencia nace de observar que la estructura reflexiva de la consciencia es una interpretación ampliada de lo que la mayoría de los neokantianos entiende por racionalidad práctica, o 'capacidad racional de establecer fines'. En este sentido, toda racionalidad práctica consistiría en una reflexión práctica que tendría por objetivo determinar la voluntad del agente mediante mandatos de habilidad, prudenciales o categóricos. Hechas estas aclaraciones, pretendo defender la idea de que toda reflexión práctica nos sumerge en una contradicción performativa que crea, cual emergente representacional en el agente, la tríada anteriormente descrita: idea de libertad, ley moral, e identidad práctica.

En otras palabras, los tres elementos descritos en el paso i), surgen al mismo tiempo en virtud de que durante la reflexión práctica el agente es capaz de verse así mismo como libre de crear un mandato con el cual podrá luego identificarse, y sentir el deber de cumplirlo. En caso de que el agente se piense como no libre durante su reflexión, esta última perdería sentido a sus ojos, lo que le movería a abandonar la tarea de querer determinar su voluntad ${ }^{16:}$ "El concepto de un mundo inteligible sólo es, por lo tanto, un punto de vista que la razón se ve obligada a adoptar fuera de los fenómenos para pensarse a sí misma como práctica (...) a no ser que deba negársele al hombre la conciencia de sí mismo como inteligencia y, por lo tanto, como causa racional y activa, o sea, como causa eficiente a través de la razón" (GMS 458). Esto no constituye una opción para el agente una vez lanzado hacia la reflexión, es decir, al 'pensarse a sí misma como práctica', sin importar que sea con arreglo a fines heterónomos o autónomos, puesto que, en virtud del alcance de la contradicción performativa, considero que aún durante la elaboración de mandatos de habilidad, el agente se apercibe como no libre respecto al fin pero aun relativamente libre frente a los medios.

La simultaneidad del surgimiento de la tríada puede también ser deducida de las contrariedades inherentes a las implicaciones que cada componente contrae individualmente. Por el lado de la idea de libertad, pues ya Kant nos ha dejado claro que desde el punto de vista de un observador, tanto frente a las acciones de los demás como a uno mismo, no podemos ofrecer prueba

${ }^{16}$ Soy consciente de que este recurso ha sido distinguidamente explotado por Apel (1985) y Habermas (1985). No obstante, mi propuesta, más bien 'minimalista', no pretende comprometerse con reglas del discurso y pretensiones de validez. En este sentido, mi propuesta guarda similitudes con los trabajos más recientes que Korsgaard ha desarrollado en torno a la autoconstitución del agente (Korsgaard 2009: 41-44) 
alguna que atestigüe la existencia de una buena voluntad. Por ello es que sólo podemos acceder a esta idea mediante el factum de la razón. Sin embargo, nos es imposible comprender el sentido y origen de la ley moral si no postulamos la idea de libertad como su ratio essendi. Certeris paribus, ambas surgen en la consciencia del agente de manera simultánea.

A esto se adhiere inexorablemente la identidad práctica. Esta entra en juego al notar que, en caso de que el agente no se identifique con ambas, nada más que normas extrañas y sin sentido serían para él. Esto significa que si no surge la identidad práctica el agente nunca podría sentir la presión de la norma sobre sus espaldas.

Así es que las fuentes de la normatividad encuentran su premisa fundamental en los supuestos epistémicos de la pregunta ‘¿qué debo hacer?’: durante la elaboración del mandato, las fuentes de la normatividad nacen de la estabilización representacional, a ojos del agente, de esta tríada. Y la evidencia textual de este punto puede encontrarse en GMS 457-458:

La causalidad de tales acciones está en él como inteligencia, así como en las leyes de los efectos y acciones con arreglo a los principios de un mundo inteligible, (...) sabiendo igualmente que, como en ese mundo él sólo es un auténtico yo en cuanto inteligencia (...), le corresponden inmediata y categóricamente, de suerte que aquello hacia lo cual le incitan inclinaciones e impulsos (...) no pueden causar quebranto alguno a las leyes de su querer en cuanto inteligencia, hasta el punto de que no se responsabiliza de esas inclinaciones e impulsos y no los imputa a su auténtico yo, esto es, a su voluntad, aunque sí se responsabilice de la indulgencia que pueda prodigar de ellas, cuando les otorga un influjo sobre sus máximas en detrimento de la ley racional de la voluntad. Al adentrarse en un mundo inteligible por medio del pensar la razón práctica no traspasa sus confines (...) Lo primero sólo es un pensamiento negativo con respecto al mundo sensible, según el cual este último no da ninguna ley a la razón en la determinación de la voluntad, y sólo es positivo en este único punto: que esa libertad, en cuanto determinación negativa, va unida al mismo tiempo con una capacidad (positiva) e incluso con una causalidad de la razón, a la que nosotros llamamos una voluntad, capacidad para obrar de tal modo que el principio de las acciones sea conforme a la moralidad esencial de una causa racional, es decir, a la condición de que la validez universal de la máxima sea homologable con la de una ley.

La tesis de la realización performativa de aquella tríada representacional podría ser la explicación de por qué para Kant resulta imposible dar cuenta del simultáneo surgimiento de la consciencia de la libertad, y de la ley moral (KpV 46).

iii) La cuestión de si Kant es realista o constructivista puede reformularse, cambiando con ello ligera, pero provechosamente, el abordaje del problema. Acuerdo con Sensen en que, para Kant, lo único portador de un valor interno es la idea de libertad. Pero en principio no estoy de acuerdo con él respecto de que en sí misma, esta idea constituya un valor moral, pues, si bien esto podría haber sido algo impensable en el siglo XVIII, en la actualidad uno puede preguntarse por qué un valor absoluto es al mismo tiempo un valor moral. La lectura de Sensen enfatiza el componente cognitivo impreso en la ley moral: la ley moral me pone en conocimiento de la incondicionalidad del valor de la libertad en su sentido práctico. Pero interno, sin equivalente, podría no referir a un valor moral. Un valor absoluto bien podría ser ontológico, estético, cognitivo o moral. En virtud de ello es que para abordar el asunto me propongo defender la idea de que en principio, la incondicionalidad del valor de la libertad es indeterminada, es no normativa, aunque, ciertamente, capaz de volverse normativa durante la reflexión práctica.

Para explicarme mejor he de precisar aún más mi abordaje. Siguiendo a Alison Hills, la discusión neokantiana contemporánea puede sustituir la distinción entre constructivismo y realismo por aquella que distingue entre los modelos atributivistas y 'constitutivistas'. Ella observa que mientras el constructivismo defiende un modelo de atribución de valor, alegando que la razón es la fuente de consideración axiológica de posibles objetos de nuestra voluntad, el realismo asume un modelo constitutivo al alegar que el acto reflexivo de deliberar expresa y realiza la subjetividad racional (Hills 2008: 187). En este marco, Hills sostiene que el ejercicio de la racionalidad práctica despliega la subjetividad racional que previamente ha de considerarse como un valor absoluto y moral, pre-existente al ejercicio mismo. 
Pero a diferencia de Hills, y bajo el abrigo del argumento performativo, no creo que sea necesario concluir con la idea realista del valor moral de la racionalidad práctica. Por el contrario, entiendo que si en este preciso momento nos representamos la idea de libertad nos vendrá a la mente aquella que Kant describiera en la "Dialéctica" de KrV: la idea de una causalidad que se causa a sí misma, y que podría ser nuestra voluntad; y en este sentido, la idea de libertad es forzosamente no normativa. 'Sólo si' entramos en una reflexión práctica que, como he dicho, nos sumerge en la tríada descrita más arriba, 'entonces' la idea de libertad asume una evidente normatividad ${ }^{17}$. Si en lugar de entender la autoconstitución de la razón en el sentido de Hills, concebimos la libertad en términos de 'valor interno', es decir, en términos de un valor absoluto no normativo, podemos sostener la tesis de que la idea de libertad, en tanto ratio essendi del IC, es capaz de desdoblarse en este último fundando su normatividad inherente cual forma de 'autoconstituir la dignidad' del agente en cuanto que lo constituye como agente: en otras palabras, un valor 'absoluto' presente en la idea de libertad que se busca realizar a sí misma a través de la buena voluntad, dado que "el auténtico destino de la razón tiene que consistir en generar una voluntad buena en sí misma" (GMS 396). Así es que la forma del IC, en tanto "voluntad que se toma por ley a sí misma", se presenta como la fuente de la normatividad inherente al deber. normatividad:

Sólo en esta relación tríadica puede la libertad desplegar su rol práctico, y por tanto su

Esta Analítica evidencia que la razón pura puede ser práctica (...) y esto se demuestra mediante un factum en el que la razón pura se revela realmente práctica para nosotros (...) $\mathrm{Al}$ mismo tiempo muestra que este factum se halla inseparablemente entrelazado con la conciencia de la libertad de la voluntad, hasta el extremo de identificarse con ella, con lo cual la voluntad de un ente racional que, como perteneciente al mundo de los sentidos, se reconoce sometido necesariamente a las leyes de la causalidad como cualquier otra causa eficiente, por otro lado en el terreno de la praxis cobra conciencia de que simultáneamente, como ser en sí mismo, su existencia es determinable en un orden inteligible de las cosas (...) si se nos atribuye libertad, ésta nos transfiere a un orden de cosas inteligible (KpV 42).

Desde esta perspectiva, la posibilidad de construcción, y por tanto, de atribución de valor, constituye la genuina expresión de un valor absoluto supuesto y asumido durante la construcción. En otras palabras: es imposible construir un mandato sin asumir realistamente la idea de libertad. Llegados a esta instancia argumental, deseo diferenciar mi enfoque de los restantes insistiendo en que es crucial no olvidar que las diferentes formulaciones del IC constituyen 'juicios sintéticos a priori' (GMS 454), lo que significa que representan acciones del sujeto dentro del sentido interno de su yo, es decir, son acciones en el tiempo (KpV 97-98). Esto implica un movimiento de la idea de libertad que va desde su sentido 'negativo' hacia su sentido 'positivo', un transcurrir de la reflexión práctica mediante la que se construye el juicio, y en tanto acción, realiza el valor absoluto de la idea de libertad a través del deber y su presión sobre el agente. Es este movimiento, o acción del sujeto en el tiempo, el que presenta a ojos del agente un cambio cualitativo que va desde el rol gnoseológico hacia el normativo de la idea de libertad, una vez que esta se conecta con la ley moral y la identidad práctica $^{18}$.

Este movimiento, en el cual la "voluntad se toma como ley a sí misma" (Schönecker 2013: 225-245), queda textualmente evidenciado en la modalidad argumental que Kant desarrolla en el segundo capítulo de la Fundamentación. Allí Kant sostiene que la fundamentación moral ha de poder trazarse entre una perspectiva deontológica y otra teleológica (GMS 437 nota de Kant) ${ }^{19}$, esto es, una modalidad argumental que además de contar con un momento de fundamentación moral, busque

${ }^{17}$ Para la distinción entre los roles epistemológicos y morales de la 'misma' idea de libertad, vid. Allison 2006: 381-415, 1990: 243-245

${ }^{18}$ Enfatizar que la característica distintiva de los juicios sintéticos a priori recae en ser una acción del sujeto en el tiempo, destaca su componente más novedoso y consistente frente a las usuales objeciones. Pienso que comprender tales juicios desde la óptica de los mandatos ilustra mejor las pretensiones de Kant para con ellos que desde la óptica de los ejemplos geométricos y matemáticos, pues difícilmente alguien pretendería interpretar las formulaciones del IC como meras deducciones. Para estas observaciones me apoyo en Felix Grayeff (1951: 87) y Rainer Stuhlmann-Laeisz (1976).

${ }^{19}$ Vid. Jesús Conill 1991: 64 ss, para una reconstrucción del uso kantiano de esta forma de fundamentación. 
realizarse en el mundo ${ }^{20}$. Este juego entre deón y thelos expresa el movimiento de la acción del sujeto en el tiempo, el momento en el cual el agente entra en una reflexión práctica que performativamente le imposibilita pensarse como no libre, una vez que se reconoce e identifica como autor de un mandato.

La idea de cotejo entre deón y thelos que tengo en mente busca eliminar la distinción entre medios y fines, reconociendo en su lugar movimientos de 'realizaciones' performativas. Piénsese en el caso de un individuo que, dada una prescripción médica, 'debería' andar en bicicleta para mejorar su salud cardíaca. Un modo heterónomo, y equivocado de abordar este caso sería interpretar la acción de andar en bicicleta como un medio para lograr el fin 'salud'. Pero la relación deontológicoteleológica nos ofrece una perspectiva moral vinculante entre la ley y el agente, asumiendo, por ejemplo, que al andar en bicicleta se está 'siendo' saludable. Este 'siendo' sólo puede significar el movimiento realizatorio de un valor ineludible una vez que se entra en la reflexión práctica, pues de lo contrario el 'deber' de andar en bicicleta presionaría 'heterónomamente' al agente.

Por otro lado, la tríada performativa puede articular los modelos atributivo y receptivo de la razón al ofrecer un gozne entre ambos: la idea de libertad en un sentido no normativo. De esta forma es posible evitar la arbitrariedad realista de encontrar en la naturaleza racional un valor axiológico preexistente a la reflexión, así como también aquel solipsismo constructivista incapaz de autojustificarse. El papel que juega la identidad práctica de Korsgaard dentro de esta argumentación es fundamental, no para depositar en ella las fuentes de la normatividad, sino más bien para encontrar allí el nexo vinculante del 'auténtico destino de la razón': la realización de la libertad a través de una ley que el sujeto asume como expresión de su yo.

Finalmente, el modelo constitutivista también incorpora el modelo atributivo en otro sentido. La reflexión aquí también es concebida como la actividad consciente de fundar las acciones en razones, capaz de atribuir valor, moral y no moral a nuestras acciones. De hecho, es razonable pensar que la actividad de elegir y elaborar mandatos de habilidad, de prudencia y moralidad, expresa con diferentes 'profundidades', al decir de Korsgaard, lo que hace digno al agente: su naturaleza 'problemáticamente' libre (Hills 2008: $194 \mathrm{ss})^{21}$.

iv) En lo que sigue me abocaré a la tarea de alimentar el modelo constitutivista que he esbozado aquí, con evidencia textual. En particular, con pasajes en los que Kant se muestra convencido de que el valor absoluto de la Humanidad, esto es, su dignidad, no yace per se en el agente, sino que es susceptible de ser 'perdido, realizado y mantenido', lo que da cuenta de la conexión entre deón y thelos. Desde el presente enfoque esto no compromete a Kant con un proyeccionismo, ni tampoco con un detectivismo, sino con ambos.

De los pasajes que pueden encontrarse en sus Lecciones de Ética, resulta de mayor claridad aquel en el cual Kant afirma que "[q]uien carece de valor interno alguno ha degradado su persona y es incapaz de practicar cualquier otro deber" (V-Mo/Collins 344). Esta afirmación nos obliga a preguntarnos acerca de cómo es posible que un individuo carezca de valor interno. Como sugiere en V-Mo/Collins 343-344, el valor interno merece respeto en la medida que se ejerce y, por el contrario, menosprecio en la medida que no se ejerce:

Estos deberes [para con uno mismo] se basan en el hecho de que carecemos de una libertad ilimitada con respecto a nuestra persona e indican que hemos de respetar a la humanidad en nuestra propia persona, porque sin esa estima el hombre se convierte en objeto de menosprecio, en algo que es sumamente reprobable desde fuera y que carece de valor interno alguno en sí mismo.

Estos pasajes no pueden leerse en las solas claves realistas o constructivistas, puesto que el valor parecería conferirse desde la idea de humanidad hacia la persona del agente, mediante el correcto uso

${ }^{20} \mathrm{Si}$ bien Christine Korsgaard analiza este mismo punto (Korsgaard 1986), no hace justicia a las implicancias constitutivistas que la reflexión conlleva para la formación de la agencia del sujeto. Pienso que su afán por adscribir al constructivismo le lleva a omitir las ventajas de un enfoque que incorpore cierto tipo de realismo.

${ }^{21}$ Las reflexiones que Korsgaard (2008: 27-68) elabora en torno a la normatividad inherente a la racionalidad prudencial cobran nueva significación desde este enfoque, en la medida que tal normatividad instrumental podría interpretarse como un momento de libertad del agente. 
de su libertad. Por ello Kant asegura que aquel que no se trata a sí mismo como un fin 'carece' de valor interno, lo que bien podría significar que el valor interno puede perderse, o desarrollarse.

No obstante, en la mayoría de los pasajes Kant se preocupa por las acciones que devienen en la pérdida de dignidad: "Mas quien ha contravenido los deberes para consigo mismo carece de valor alguno. La violación de los deberes para con uno mismo despoja al hombre de todo su valor en términos absolutos" (V-Mo/Collins 341). De hecho, todos los vicios que Kant denomina crimina corporis, implican una instrumentalización de sí mismo, dado que "[q]uien hace algo que le impida seguir siendo un fin se utiliza a sí mismo como un medio y hace de su persona una mera cosa" (V$\mathrm{Mo} /$ Collins 343), lo que "rebaja la dignidad del género humano en su propia persona" (V-Mo/Collins 342), o más gravemente aún, le desposee "de su dignidad personal" (V-Mo/Collins 346). A la luz de ello, Kant insiste en que el agente debe alcanzar un 'dominio sobre sí mismo' que le permita dignificar su persona mediante el cumplimiento del deber:

tratándose de la moralidad no hemos de atender sino a lo que perfeccione nuestro valor interno y mantenga la dignidad de la condición humana con respecto a nuestra propia persona, para lo cual debemos someter a nuestro propio arbitrio de modo que nuestras acciones resulten adecuadas con los fines primordiales de la humanidad (V-Mo/Collins 363)

Esta adecuación a los fines de la primordiales de la humanidad depende de cuánto pueda el agente encauzar sus acciones hacia ellos, esto es, hacia el fin de crear una ley capaz de compatibilizar las libertades de todos los individuos: "[s]ólo aquellas condiciones bajo las cuales es posible el mayor uso de libertad, de modo que ésta pueda coincidir consigo misma, son los fines primordiales de la humanidad" (V-Mo/Collins 346).

Pero, cuando Kant desciende al 'infierno de la casuística', al decir de Roberto R. Aramayo, entiende que el hombre per se carece de las capacidades suficientes para dar cumplimiento a los fines primordiales de la humanidad, es decir, para la realización de la libertad mediante la ley moral. Y el problema consiste en que: "el dominio sobre nosotros mismos se ve todavía dificultado por el hecho de que la ley moral dispone de prescripciones, más no de móviles; (...) el dominio de uno mismo estriba en la fortaleza del sentimiento moral" (V-Mo/Collins 361).

Tal "fortaleza del sentimiento moral" requiere de disciplina (Pädagogik 442 ss; KpV 152), puesto que aunque uno "lo haya perdido todo, posee dentro de sí algo que detenta un valor intrínseco y se hace acreedor de nuestra compasión" (V-Mo/Collins 367-368). Kant asegura que el individuo tiene el deber de encauzar su libertad personal hacia la evitación del mal moral, y la realización de la libertad a través de la ley moral. En otras palabras: el hombre tiene el deber de 'realizar' la libertad, en virtud de que "[t]ales deberes, así como la dignidad del género humano, exigen que el hombre se despoje de toda pasión y afecto; ésta es la regla, pero otra cosa es que los hombres puedan llegar realmente tan lejos" (V-Mo/Collins 368). De este modo, Kant parecería afirmar que 'si y sólo si' el hombre logra forjarse un carácter favorable hacia los fines de la humanidad, 'entonces' podría hacerse acreedor de respeto:

Pero el hombre no ha de ser tanto digno de ser amado como digno de estimación y respeto. Un hombre recto y concienzudo, que no sea parcial y no admita regalo alguno, no es objeto de amor; al ser escrupuloso en lo que se acepta, pocas de sus acciones pueden deberse a la magnanimidad y al amor, con lo que no resulta digno de ser amado por los demás, su felicidad se cifra en ganarse la estima de los otros y la virtud constituye su auténtico valor interno (V-Mo/Collins 358).

Sólo la 'virtud' de cierta forma de vida, muy semejante a la estoica (V-Mo/Collins 367; KpV 84), puede permitirle al individuo asumir la Humanidad en su propia persona. Y esta 'disposición de ánimo' consiste en realizar la libertad a través de la reflexión.

Kant sostiene que el mal moral también es producto de la libertad, en razón de que "es peor obrar mal en base a máximas que hacerlo por inclinación, dado que las máximas son fruto de la reflexión" (V-Mo/Collins 368). La reflexión constituye el ámbito performativo realizativo de la libertad a causa de que "el buen comportamiento sólo puede derivarse de la adopción de ciertas máximas". Esto explica por qué para él "[n]o hay nada más enojoso y aborrecible que inventarse así 
una ley para esquivar la verdadera": "Por muy a menudo que el hombre haya infringido la ley moral puede enmendarse todavía (...) Pero quien se ha fabricado una ley falsa y propicia detenta un principio para su maldad, y no cabe esperar que se enmiende" (V-Mo/Collins 359).

Los términos 'inventarse' y 'fabricarse' ciertamente refieren a la acción del agente de construir el mandato con el cual ha de determinar su voluntad. No obstante, la libertad necesita una regla que le permita 'coincidir con ella misma', y esta regla es el incipiente IC que hallamos en las Lecciones de Ética. Esta es la ley con la cual el agente ha de evaluar si es merecedor de estima o no, y la que augura la bicondicionalidad entre la idea de libertad y ley moral, descrita en la $\mathrm{KrV}^{22}$ :

En todos los deberes para con uno mismo subyace cierto pundonor, que consiste en la autoestima del hombre, en no aparecer como indigno ante sus propios ojos, en que sus acciones se compadezcan con el concepto de humanidad. El honor interno de ser dignos a los propios ojos, la valoración del asentimiento, es parte esencial de los deberes para con uno mismo (V-Mo/Collins 347).

Kant muestra la sensibilidad suficiente como para dar cuenta de que el hombre se haya de cara a un gran desafío moral: nada más y nada menos que el desafío de tener que 'autoconstituirse' racionalmente conforme al thelos de la libertad, manifiesto en las exigencias de su deón, es decir, del IC. La 'apodicticidad' del deber moral se le presenta al agente 'ante sus propios ojos' cada vez que asume la tarea de responder '¿qué debo hacer?' Este foro interno de reflexión en el que emerge la realización performativa, le permite al agente sentir sobre sus hombros la presión de la ley; y en caso de que este se sacuda tal presión de sí, surgirá el peligro de destruir o desvirtuar las condiciones necesarias y suficientes de la reflexión que le hacen portador de dignidad: la idea de libertad, la ley moral, y la identidad práctica, hipotecando así su calidad de agente ${ }^{23}$ : "la observancia de la moralidad es algo sublime. Es preferible sacrificar la vida que desvirtuar la moralidad. Vivir no es algo necesario, pero sí lo es vivir dignamente; quien no puede vivir dignamente no es digno de la vida" (VMo/Collins 373) ${ }^{24}$.

El juego de palabras final sugiere que es preciso constituir la propia agencia para luego volvernos dignos de vivir, algo que, ciertamente, sólo se puede realizar en vida. Tal obviedad revela la conexión ético-moral que traza Kant, y evidencia la conexión teleológico-deontológica anteriormente señalada en su Fundamentación. Una vez que esta conexión se pierde de vista corremos el peligro de caer en polarizaciones infundadas, dirimiendo excluyentemente entre lo ético y lo moral, entre el atribuir y descubrir valores, entre lo universal formal y lo particular concreto; y el modelo constitutivista desaparece.

\section{Reflexiones finales}

Luego de reconstruir los enfoques constructivistas y realistas más destacados, he intentado indicar sus limitaciones más importantes, y sugerir que las ambigüedades proyeccionistas y detectivistas de la postura de Korsgaard insinúan, cual síntoma, cierta falencia en las formas de debatir acerca de las fuentes kantianas de la normatividad ${ }^{25}$. He considerado tales síntomas como señales de la injustificada forma de abordar los textos kantianos, para luego aventurarme a esbozar lo que entiendo como un mejor modo de comprenderlos.

Hacia el final he argumentado en favor de un modelo constitutivista que aspira a absorber las virtudes y los aportes del constructivismo y realismo con el objetivo de superar sus diferentes

\footnotetext{
${ }^{22}$ Sobre la coherencia interna existente entre las Lecciones de Ética, la Crítica de la Razón Práctica y la Fundamentación, vid. Roberto R. Aramayo 1986.

${ }^{23}$ Pienso que la constitución de la agencia del sujeto por medio de la reflexión ayuda a comprender la idea fundamental de libertad kantiana que podría subyacer a sus diferentes usos (libertad empírica, moral o autónoma, espontánea, trascendental y como postulado). Además de la tesis de Korsgaard, en este punto convergen los trabajos que Henry Allison (1996: 129-154) ha desarrollado.

${ }^{24}$ Sobre la base de estas afirmaciones puede echarse cierta luz sobre aquella convicción kantiana respecto de que la dignidad de ser felices precede al interés mismo por la felicidad: KpV 130 ss; GMS iv 393; KrV A 806-B834 / A 807-B835.

${ }^{25}$ Esta forma de reconstruir el debate entre neokantianos guarda similitudes con la que realiza Paul Formosa (2011). No obstante nuestras propuestas en torno a cómo comprender las fuentes de la normatividad difieren radicalmente. Opino que el por demás interesante 'constructivismo débil' de Formosa, capaz de incorporar cierto tipo de realismo, no asume el paso definitivo hacia lo que aquí defiendo, a saber, que en el caso kantiano, no puede sostenerse ninguno de los modelos sin presuponerse el otro.
} 
limitaciones. Pienso que la conclusión más acorde al desarrollo de este trabajo sería la de afirmar que Kant, y su programa moral, es tanto constructivista como realista al mismo tiempo, puesto que es performativamente imposible abocarse a la tarea de elaborar un mandato sin asumir al mismo tiempo que se está realizando la subjetividad racional de forma libre. Esto también nos tienta a pensar en la posibilidad de que, a corto o mediano plazo, podamos arribar a la misma y radical conclusión que da fin al diálogo de Eutifrón: la de que el dilema entre atribución y recepción del valor es falso.

Bibliografía

ALLISON, Henry E.: "Kant on freedom of the will", en GUYER, P. (ed.): The Cambridge Companion to Kant and Modern Philosophy, Cambridge, Cambridge University Press, 2006, 381-415.

ALLISON, Henry E.: Idealism and Freedom. Essays on Kant's Theoretical and Practical Philosophy, Cambridge, Cambridge University Press, 1996.

ALLISON, Henry E.: Kant's Theory of Freedom, Cambridge, Cambridge University Press, 1990.

APEL, Karl-Otto: "La ética del discurso como la ética de la responsabilidad. Una transformación posmetafísica de la ética de Kant”, en APEL, K. O.: Teoría de la verdad y ética del discurso, Barcelona, Paidós, 1998, 147-184.

APEL, Karl-Otto: "El a priori de la comunidad de comunicación y los fundamentos de la ética (1967)", en APEL, K. O.: La transformación de la filosofía, (trad. A. Cortina, J. Chamorro y J. Conill), vol. 2, Madrid, Taurus, 1985, 341-413.

BENHABIB, Seyla: "The Generalized and the Concrete Other. The Kohlberg-Gilligan Controversy and Moral Theory", Praxis International 5, 4 (1986) 402-424.

COHEN, G. A.: "Reason, Humanity, and The Moral Law", en KORSGAARD, C. M.: The Sources of Normativity, New York, Cambridge University Press, 1996, 207-234.

CONILL, Jesús: El enigma del animal fantástico, Madrid, Tecnos, 1991.

FITZPATRICK, William J.: "The Practical Turn in Ethical Theory: Korsgaard's Constructivism, Realism, and the Nature of Normativity", Ethics 115 (2005) 651-691.

FORMOSA, Paul: "Is Kant a Moral Constructivist or a Moral Realist?", European Journal of Philosophy 21, 2 (2011) 1-27.

GRAYEFF, Felix: Deutung und Darstellung der theoretischen Philosophie Kants, Hamburg, Felix Meiner, 1951.

GUYER, Paul: Kant on Freedom, Law, and Happiness, Cambridge, Cambridge University Press, 2000.

GUYER, Paul: "The Value of Reason and the Value of Freedom", Ethics 109 (1998) 22-35.

HABERMAS, Jürgen: "Ética del discurso. Notas sobre un programa de fundamentación", en HABERMAS, J.: Conciencia moral y acción comunicativa, Barcelona, Península, 1985, 57134.

HERMAN, Barbara: “Could It Be Worth Thinking About Kant on Sex and Marriage?", en ANTHONY, L. y WITT, Ch. (eds.): A Mind of One's Own: Feminist Essays on Reason and Objectivity, Boulder, Westview Press, 1993a, 53-72.

HERMAN, Barbara: The Practic of Moral Judgement, Cambridge, Harvarad University Press, 1993b. HILLS, Alison: "Kantian Value Realism", Ratio (new series) 21, 2 (2008) 182-200.

KORSGAARD, Christine M.: Self-Constitution. Agency, Identity, Integrity, New York, Cambridge University Press, 2009.

KORSGAARD, Christine M.: "The normativity of Instrumental Reason", en KORSGAARD, C. M.: The Constitution of Agency. Essays on Practical Reason and Moral Psychology, New York, Oxford University Press, 2008, 27-68.

KORSGAARD, Christine M.: “Aristotle and Kant on the Source of Value”, Ethics 96, 3 (1986) 486505. 
KORSGAARD, Christine M.: Las Fuentes de la Normatividad, México, UNAM, 2000.

LANGTON, Rae: "Objective and Unconditioned Value", Philosophical Review 116, 2 (2007) 157-85. LUECK, Bryan: "Kant's fact of Reason as Source of Normativity", Inquiry 52, 6 (2009) 596-608.

NINO, Carlos Santiago: El constructivismo ético, Madrid, Centro de Estudios Constitucionales, 1989. O`NEILL, Onora: Towards Justice and Virtue, England, Cambridge University Press, 1996.

O'NEILL, Onora: Constructions of Reason: Explorations of Kant's Practical Philosophy, England, Cambridge University Press, 1989.

PIPPIN, Robert B.: “Kant's Theory of Value: On Allen Wood's Kant's Ethical Thought”, Inquiry 43, 2 (2000) 239-266.

PUTNAM, Hilary: "Valores y normas", en PUTNAM, H.: El desplome de la dictioma hecho-valor y otros ensayos, Barcelona, Paidós, 2004, 133-158.

R. ARAMAYO, Roberto: "La presencia de la 'Crítica de la Razón Práctica' en las 'Lecciones de Ética' de Kant”, Ágora 7 (1986) 145-158.

RAUSCHER, Frederick: "Kant's Moral Anti-Realism”, Journal of the History of Philosophy 40 (2002) 477-499.

RAWLS, John: El liberalismo político, Barcelona, Crítica, 1996.

RAWLS, John: "Kantian Constructivism in Moral Theory", Journal of Philosophy 77 (1980) 515 572.

SCHÖNECKER, Dieter: "A free will and a will under moral law are the same", en SENSEN, O. (ed.): Kant on Moral Autonomy, New York, Cambridge University Press, 2013, 225-245.

SENSEN, Oliver: Kant on Human Dignity, Berlín, Walter de Gruyter Gmbll \& Co., 2011.

SENSEN, Oliver: "Dignity and the Formula of Humanity", en TIMMERMANN, J. (ed.): Kant's "Groundwork of the Metaphysics of Morals": A Critical Guide, Cambridge, Cambridge University Press, 2010, 102-118.

SENSEN, Oliver: "Kant's Conception of Inner Value", European Journal of Philosophy 19, 2 (2009) 262-280.

STUHLMANN-LAEISZ, Rainer: Kants Logik, Berlín-New York, Walter de Gruyter, 1976.

WOOD, Allen: Kant's Ethical Thought, Cambridge, Cambridge University Press, 1999.

YOUNG, Marion Iris: "The Ideal of Impartiality and the Civic Public: Some Implications of Feminist Critiques of Moral and Political Theory”, Praxis International 5, 4 (1986) 381-401. 